\title{
Genome-wide association study using high-density single nucleotide polymorphism arrays and whole-genome sequences for clinical mastitis traits in dairy cattle ${ }^{1}$
}

\author{
G. Sahana, ${ }^{* 2}$ B. Guldbrandtsen, ${ }^{*}$ B. Thomsen, $\dagger$ L-E. Holm, $†$ F. Panitz, $†$ R. F. Brøndum, ${ }^{*}$ C. Bendixen, $\dagger$ \\ and M. S. Lund* \\ ${ }^{*}$ Center for Quantitative Genetics and Genomics, Department of Molecular Biology and Genetics, Aarhus University, 8830 Tjele, Denmark \\ †Molecular Genetics and Systems Biology, Department of Molecular Biology and Genetics, Aarhus University, 8830 Tjele, Denmark
}

\begin{abstract}
Mastitis is a mammary disease that frequently affects dairy cattle. Despite considerable research on the development of effective prevention and treatment strategies, mastitis continues to be a significant issue in bovine veterinary medicine. To identify major genes that affect mastitis in dairy cattle, 6 chromosomal regions on Bos taurus autosome (BTA) 6, 13, 16, 19, and 20 were selected from a genome scan for 9 mastitis phenotypes using imputed high-density single nucleotide polymorphism arrays. Association analyses using sequence-level variants for the 6 targeted regions were carried out to map causal variants using whole-genome sequence data from 3 breeds. The quantitative trait loci (QTL) discovery population comprised 4,992 progeny-tested Holstein bulls, and QTL were confirmed in 4,442 Nordic Red and 1,126 Jersey cattle. The targeted regions were imputed to the sequence level. The highest association signal for clinical mastitis was observed on BTA 6 at $88.97 \mathrm{Mb}$ in Holstein cattle and was confirmed in Nordic Red cattle. The peak association region on BTA 6 contained 2 genes: vitamin D-binding protein precursor $(G C)$ and neuropeptide FF receptor 2 (NPFFR2), which, based on known biological functions, are good candidates for affecting mastitis. However, strong linkage disequilibrium in this region prevented conclusive determination of the causal gene. A different QTL on BTA 6 located at $88.32 \mathrm{Mb}$ in Holstein cattle affected mastitis. In addition, QTL on BTA 13 and 19 were confirmed to segregate in Nordic Red cattle and QTL on BTA 16 and 20 were confirmed in Jersey cattle. Although several candidate genes were identified in these targeted regions, it was not possible to identify a gene
\end{abstract}

\footnotetext{
Received March 16, 2014

Accepted July 14, 2014.

${ }^{1}$ The results presented here are part of a patent application number PCT/EP2013/067838 entitled "Genetic markers for mastitis resistance" (AU-2012-634-489).

${ }^{2}$ Corresponding author: Goutam.Sahana@agrsci.dk
}

or polymorphism as the causal factor for any of these regions.

Key words: dairy cattle, quantitative trait locus, mastitis, NGS

\section{INTRODUCTION}

Association mapping aims to identify specific genetic variants (i.e., loci and alleles) associated with phenotypic differences in traits. Genome-wide association studies (GWAS) evaluate associations between common genetic variants with phenotypic difference in a trait. Recent advances in our understanding of genetic variation and the technologies that measure such variation have made GWAS more tractable.

Previous mapping studies have identified QTL that affect clinical mastitis (CM) and SCC in cattle (e.g., Lund et al., 2007, 2008; Sahana et al., 2008, 2013; Cole et al., 2011; Meredith et al., 2013; Abdel-Shafy et al., 2014). These studies, however, were not able to pinpoint specific candidate gene variants. Today, with increased availability of high-density (HD) SNP arrays and whole-genome sequence data, the chances of identifying causative mutations are higher. Identifying causal variants or assigning QTL to one gene or a few genes through association mapping may facilitate identification of genes that control mastitis resistance. However, the linkage disequilibrium (LD) in cattle spreads over large regions of the genome (de Roos et al., 2008), which may hinder the identification of one or a few causal variants. Therefore, multiple breed data may be used to provide more precise localization.

Unfavorable genetic correlations have been detected between milk production and CM (from 0.21 to 0.55 ; Heringstad et al., 2005), which are caused by pleiotropic effects and linkage. Understanding the underlying pleiotropic connections between quantitative traits is important for predicting correlated responses to artificial selection. Therefore, identifying QTL that affect milk production traits and mastitis may increase understanding of the genetic determinants of milk production and CM. 


\section{QTL Discovery}

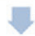

$4992 \mathrm{HOL}$ genotyped with 50k were imputed to HD using $557 \mathrm{HOL}$ reference

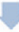
GWAS for nine mastitis traits with imputed HD data

$\sqrt{8}$

Top six regions were targeted (TRs)

TRs were imputed to sequence level using reference of 89 bulls from HOL, RDC and JER

$\sqrt{2}$

Region-wise association study for the TRs

$\sqrt{2}$

Reanalysis of the TRs with 'top' SNP as cofactor to test for multiple causal factors

\section{QTL Confirmation}

(5)

Imputed HD genotypes for 4442 RDC and 1126 JER were imputed to full sequence level using 253 WGS from the 1000 Bull genome project

$\sqrt{2}$

Genotypes for the six TRs were extracted

$\sqrt{2}$

Within breed association analyses for the 6 TRs in RDC and JER

Meta-analysis for the six TRs using RWAS results from three cattle populations

Figure 1. Flowchart of steps for association study for mastitis QTL discovery in Holstein (HOL) cattle and confirmation studies in Nordic Red (RDC) and Danish Jersey (JER) cattle. 50k = 50,000 markers; HD = high density; GWAS = genome-wide association study; WGS = whole-genome sequence; RWAS = region-wise association study. Color version available in the online PDF.

The objectives of the present study were to (1) identify QTL for CM in Nordic Holstein cattle using HD SNP arrays and then fine-map targeted QTL using sequence-level variants, (2) confirm selected QTL in Danish Jersey and Nordic Red cattle to determine whether targeted QTL segregate in these 2 breeds, (3) determine whether multiple-breed data contribute to identification of causative genes or mutations, and (4) examine targeted QTL for association with milk production traits.

\section{MATERIALS AND METHODS}

A flowchart of the materials and methods of this study (i.e., populations studied, genotype imputation, and association analyses) is presented in Figure 1.

\section{Nordic Holstein Cattle}

Genome scans for mastitis resistance were carried out for 9 mastitis phenotypes in Nordic Holstein cattle. Udder health traits currently evaluated in the Nordic Cattle Genetic Evaluation (http://www. nordicebv.info) included 4 clinical mastitis traits (all coded as binary traits) and 3 SCC traits from the first 3 lactations (Table 1). These indices were standardized to a mean of 100 and a standard deviation of 10 (Johansson et al., 2007). Estimated breeding values were available for 4,992 progeny-tested Nordic Holstein bulls with the 9 mastitis-related phenotypes. Most of these bulls were born between 1986 and 2009; a few older bulls (43) were also included. The SNP 
Table 1. Abbreviations and definitions of 9 mastitis traits included in the study

\begin{tabular}{ll}
\hline $\begin{array}{l}\text { Trait } \\
\text { abbreviation }\end{array}$ & Trait definition \\
\hline CM11 & Clinical mastitis $(1)$ or not $(0)$ between -15 and $50 \mathrm{~d}$ after first calving \\
CM12 & Clinical mastitis (1) or not (0) between 51 and $305 \mathrm{~d}$ after first calving \\
CM2 & Clinical mastitis (1) or not (0) between -15 and $150 \mathrm{~d}$ after second calving \\
CM3 & Clinical mastitis (1) or not (0) between -15 and $150 \mathrm{~d}$ after third calving \\
CM & Clinical mastitis index: $0.25 \times$ CM1 $+0.25 \times$ CM12 $+0.3 \times$ CM2 $+0.2 \times$ CM3 \\
SCC1 & Log SCC average in first lactation \\
SCC2 & Log SCC average in second lactation \\
SCC3 & Log SCC average in third lactation \\
SCC & Somatic cell count index: $0.5 \times$ SCC1 $+0.3 \times$ SCC2 $+0.2 \times$ SCC3 \\
\hline
\end{tabular}

genotypes and EBV of the bulls were used for association mapping.

\section{SNP Array Genotyping}

Genotyping of bulls was performed using the Illumina Bovine SNP50 BeadChip (Illumina Inc., San Diego, CA) at Aarhus University (Tjele, Denmark) and at GenoSkan A/S (Tjele, Denmark). The quality parameters used for selection of SNP were minimum call rates of $85 \%$ for individuals and $95 \%$ for loci. The vast majority of individuals had call rates in excess of $99 \%$. Marker loci with minor allele frequencies (MAF) below $5 \%$ and deviation from Hardy-Weinberg proportion $(P<0.00001)$ were excluded. The minimal acceptable GenCall score (Illumina Inc.) was 0.60 for individual typings, and individuals with average GenCall scores below 0.65 were excluded. The number of SNP remaining after quality control was 43,415 in the 50,000-marker $(\mathbf{5 0 K})$ data set. In addition, a total of 557 Holstein bulls in the EuroGenomics project (Lund et al., 2011) were genotyped using the Illumina BovineHD Genotyping BeadChip (Illumina Inc.), and data were available for genotype imputation. A total of 777,962 SNP on the BovineHD BeadChip were distributed across the entire bovine genome, with an average gap size of 3.43 $\mathrm{kb}$ and a median gap size of $2.68 \mathrm{~kb}$. Quality control parameters for HD data were similar to those for the 50K chip described above. Those markers included on the 50K chip but not on the HD chip were excluded from imputation. The number of SNP, after imputation to the BovineHD chip, was 648,219 . The $50 \mathrm{~K}$ genotypes were imputed to the HD genotypes with the BEAGLE software package (Browning and Browning, 2009) using the HD genotyped bulls as references (Su et al., 2011). The genome positions of the SNP were taken from the UMD3.1 Bovine genome assembly (Zimin et al., 2009).

\section{Whole-Genome Sequencing}

Whole-genome sequencing was performed on 89 bulls (32 Nordic Holstein, 30 Danish Red, and 27 Danish
Jersey cattle). The DNA was extracted from semen samples using standard procedures. Shotgun, pairedend sequencing with a read length of $91 \mathrm{bp}$ was performed using Illumina Inc. sequencers at the Beijing Genomics Institute (Shenzhen, China).

Sequence data were analyzed by converting FASTQ data from Illumina to Sanger quality encoding (Wellcome Trust Sanger Institute, Hinxton, UK) using a patched version of MAQ software (Li et al., 2008). Average genome coverage was at least $10 \times$. Reads were aligned to the UMD3.1 assembly of the cattle genome (Zimin et al., 2009) using Burrows-Wheeler Aligner (BWA) software (Li and Durbin, 2009) and converted to BAM files using Sequence Alignment/Map (SAMtools) software (Li et al., 2009). Quality scores were recalibrated using the Genome Analysis Toolkit (GATK; McKenna et al., 2010) following the Human 1000-Genome (http://www.1000genomes.org/) guidelines.

After alignment of sequence reads to the cattle reference genome, candidate sites, regions at which one or more samples differed from the reference sequence, were identified. The Genome Analysis Toolkit was used to realign sequences, insertion/deletions, and call variants, incorporating information from the dbSNP database (version 133; Sherry et al., 2000). Variants with low phred scores were discarded, and only biallelic polymorphisms were imputed. The variants calls (i.e., the estimation of alleles present in each individual at variant sites) were carried out using VCF tools (http:// vcftools.sourceforge.net/). More than 23 million DNAlevel variants, including SNP, insertion-deletions (indels), and copy number variants, were observed across the 3 cattle breeds (our unpublished data). Variants were annotated using the Variant Effect Predictor software (McLaren et al., 2010).

\section{Targeted Imputation to Full Genome Sequence}

Six chromosomal regions were selected based on a GWAS using the HD SNP array on 9 mastitis traits in Nordic Holstein cattle. The lengths of regions and the number of SNP (based on whole-genome sequence 
Table 2. Six targeted regions selected based on the genome-wide association study with the BovineHD BeadChip SNP array (Illumina Inc., San Diego, CA $)^{1}$

\begin{tabular}{lcccl}
\hline Chromosome & $\begin{array}{c}\text { Region } \\
(\mathrm{Mb})\end{array}$ & $\begin{array}{c}\text { Region } \\
\text { length }(\mathrm{Mb})\end{array}$ & $\begin{array}{c}\text { No. of SNP in the } \\
\text { targeted region }\end{array}$ & $\begin{array}{l}\text { Traits showing genome-wide } \\
\text { significant association }\end{array}$ \\
\hline BTA 5 & $84-95$ & 11 & 55,046 & All 5 clinical mastitis traits \\
BTA 6 & $88-96$ & 8 & 41,993 & All 9 traits \\
BTA 13 & $57-63$ & 6 & 18,935 & All traits except first-lactation SCC \\
BTA 16 & $48-55$ & 7 & 27,709 & All 9 traits \\
BTA 19 & $55-58$ & 3 & 16,145 & All traits except CM12 \\
BTA 20 & $32-40$ & 8 & 30,025 & All 9 traits \\
\hline
\end{tabular}

${ }^{1}$ Genome-wide significant is after Bonferroni multiple testing correction for BovineHD SNP $\left[-\log _{10}(P\right.$-value $\left.)>7.1\right]$

${ }^{2} \mathrm{CM} 12=$ clinical mastitis for first lactation $(51-305 \mathrm{~d})$.

data) for each region selected after quality control are given in Table 2. The HD genotypes were imputed to the sequence level for the targeted regions using BEAGLE software (Browning and Browning, 2009) and the default settings. Single nucleotide polymorphisms with imputation certainty $\geq 0.90$ were retained for association analyses. The numbers of biallelic polymorphisms for each of the 6 targeted regions are in Table 2 .

\section{Nordic Red and Danish Jersey Cattle}

For confirmation of associations, data from Nordic Red and Danish Jersey cattle were used. The number of bulls with official breeding values for clinical mastitis indices was 4,442 for Nordic Red and 1,126 for Jersey cattle. The EBV for $\mathrm{CM}$ in both cattle were available from Nordic Cattle Genetic Evaluation. Imputed HD genotypes of Nordic Red and Jersey bulls were further imputed to the sequence level using the same procedure as for Holstein cattle but with more individuals in the reference population. The reference population was obtained from whole-genome sequencing carried out at Aarhus University and bulls in the 1000 Bull Genomes Project (http://www.1000bullgenomes.com/). Whole-genome sequences from 253 dairy cattle were used as a reference to impute the HD data to the whole genome level using BEAGLE software (Browning and Browning, 2009). See Höglund (2013) for imputation to the whole-genome sequence in Nordic Red and Jersey cattle.

\section{Statistical Analyses}

A SNP-by-SNP analysis was carried out using a linear mixed model (LMM; Yu et al., 2006). Complex familial relationships are the primary confounding factor in GWAS in livestock populations. Linear mixed models, which include relationships among individuals through polygenic effects, can control false positives due to family structure and population stratification in cattle (Sahana et al., 2010; Kadri et al., 2014). For the
LMM, an association between a SNP and a phenotype was assessed by a single-locus regression analysis using the following equation:

$$
\mathbf{y}=\mathbf{1} \mu+\mathbf{m} g+\mathbf{Z u}+\mathbf{e}
$$

where $\mathbf{y}$ is the vector of phenotypes (EBV); $\mathbf{1}$ is a vector of ones; $\mu$ is the general mean; $\mathbf{m}$ is the genotype dosages (obtained from BEAGLE output; values ranged from 0 to 2) associating records to the marker effect; $g$ is the scalar additive effect of the SNP; $\mathbf{Z}$ is an incidence matrix relating phenotypes to the corresponding random polygenic effect; $\mathbf{u}$ is a vector of the random polygenic effect with the multivariate normal distribution $N\left(\mathbf{0}, \mathbf{A} \sigma_{u}^{2}\right)$, where $\mathbf{A}$ is the additive relationship matrix and $\sigma_{u}^{2}$ is the polygenic variance; and $\mathbf{e}$ is a vector of random environmental deviates with the normal distribution $N\left(\mathbf{0}, \mathbf{I} \sigma_{e}^{2}\right)$, where $\sigma_{e}^{2}$ is the error variance and $\mathbf{I}$ is an identity matrix. The model was fitted by REML using the software DMU (Madsen and Jensen, 2012), and the null hypothesis $\left(\mathrm{H}_{0}\right) g=0$ was assessed using a $t$-test.

Significant Associations. A SNP was considered significantly associated with a trait if the $P$-value was below a significance threshold after Bonferroni correction for multiple testing. We had approximately 0.65 and 9 million SNP in the HD and whole-genome sequence association analyses, respectively, and therefore genome-wide significant thresholds after Bonferroni multiple testing correction were 7.1 and 8.3, respectively. Region-wise nominal $5 \%$ significance threshold $\left[-\log _{10}(P\right.$-value $\left.)\right]$ ranged between 5.51 to 6.04 after Bonferroni correction (Table 2).

Association Analyses with the Most Important SNP as a Cofactor in the Model. As LD extends over long distances in dairy cattle (de Roos et al., 2008), a large number of SNP from targeted regions are expected to show associations with mastitis phenotypes. However, as the targeted regions were quite large ( $>5 \mathrm{Mb}$ in some cases), it was also possible that the 
effect observed was due to multiple causative variants segregating in the population. To investigate if one or multiple causal factors were located within the targeted region, SNP selected from LMM analyses were included in the model as cofactors. The LMM described above was extended as shown in Equation [2]. The analysis was then repeated for all SNP except the one used as a cofactor for the Holstein population.

$$
\mathbf{y}=\mathbf{1} \mu+\mathbf{s} b+\mathbf{m} g+\mathbf{Z u}+\mathbf{e},
$$

where $b$ is the allele substitution effect and $\mathbf{s}$ is the vector of allele doses for the SNP used as cofactors; the rest of the model terms were described for Equation [1].

Meta-Analyses. We investigated the associations between $\mathrm{CM}$ and targeted regions in 3 breeds (Holstein, Nordic Red, and Jersey). To combine information across breeds, we conducted a meta-analysis for all SNP to select the SNP with the highest associated signal across the breeds. The combined test statistic $\sum_{i=1}^{3}-2 \log _{e} P_{i}$, which follows a $\chi^{2}$ distribution with $(2 \times$ $3)=6$ degrees of freedom, where $P_{i}$ is the $P$-value from the $i$ th breed as obtained from the LMM analyses (Equation [1]).

LD Analyses. For each pair of SNP, the squared correlation coefficient $\left(\mathrm{r}^{2}\right)$ between the genotypes, coded 0,1 , or 2 to represent the number of variant alleles, was calculated. The squared correlation based on genotypic allele counts was, therefore, not identical to the $\mathrm{LD}\left(\mathrm{r}^{2}\right)$ as estimated from haplotype frequencies, although it was often very similar (Purcell et al., 2007). Because it is faster to calculate, it provides a good way to screen for genomic regions with strong LD. The $\mathrm{r}^{2}$ values for the Holstein population were estimated using the PLINK software package (Purcell et al., 2007).

Association Analyses for Milk Production Traits. Mastitis resistance is negatively correlated with milk production traits (Lund et al., 1999; Heringstad et al., 2005). Therefore, regions selected for mastitis resistance were scanned for association with 3 milk production indices: fat, protein, and milk (for details of recording and estimating breeding values for these 3 indices, see http://www.nordicebv.info). The LMM as described in Equation [1] was used for the association analyses of the 3 milk production traits.

Identification of Functionally Important Variants Within QTL. Single nucleotide polymorphisms within the chromosomal regions showing the highest associations with mastitis traits were selected for further evaluation. Furthermore, SNP within coding regions were evaluated using SIFT ( $\mathrm{Ng}$ and Henikoff, 2001) and PolyPhen-2 software (Adzhubei et al., 2010) for potential effects of amino acid substitutions. Single nucleotide polymorphisms estimated to affect protein function were evaluated for association with mastitis traits.

\section{RESULTS AND DISCUSSION}

\section{Selection of Genomic Regions for Region-Wise Association Studies}

A Manhattan plot of CM and SCC based on the HD SNP array in Holstein cattle is presented in Figures 2 and 3. Six genomic regions were selected based on the HD SNP array and region-wise association studies (RWAS) using variation at the sequence level (Table 2 ). The selection was based on association signals across multiple traits. The total number of regions was arbitrarily restricted to 6 for follow-up by RWAS.

\section{RWAS with Polymorphisms from Whole-Genome Sequences}

The association signal plots for RWAS of $\mathrm{CM}$ and SCC on BTA 5 in Holstein cattle (the LMM and the LMM with the most associated SNP as a cofactor) are presented in Figures 4 and 5, respectively, and plots for BTA 6, 13, 16, 19, and 20 are presented in Supplementary Figure S1, panels A to J (http://dx.doi. org/10.3168/jds.2014-8141). The most significant SNP associated with the 9 mastitis-related traits in Nordic Holstein cattle for each of these genomic regions, BTA $5,6,13,16,19$, and 20, are presented in Table 3 .

All 6 targeted regions had wide peaks of association. However, when including the most significantly associated SNP as cofactors, the range of associated regions collapsed except for BTA 6 (Supplementary Figure S1, panels A and B; http://dx.doi.org/10.3168/jds.20148141). This indicated that the SNP used as cofactors were either functional polymorphisms affecting mastitis resistance or they were in strong $\mathrm{LD}$ with functional polymorphism(s) in the targeted regions. These data also indicated the most likely single genetic variant within the targeted region, but due to the extent of LD, multiple causative variants could not be ruled out. Squared correlations of marker genotypes $\left(\mathrm{r}^{2}\right)$ for the 6 genomic regions under study (BTA 5, 6, 13, 16, 19, and 20) are presented in Supplementary Figure S2, panels A to F. The RWAS results from individual targeted genomic regions are presented and discussed below.

\section{Targeted Region on BTA 5}

Holstein Cattle. The most significant SNP for each of the 9 mastitis-related traits for the targeted region on 


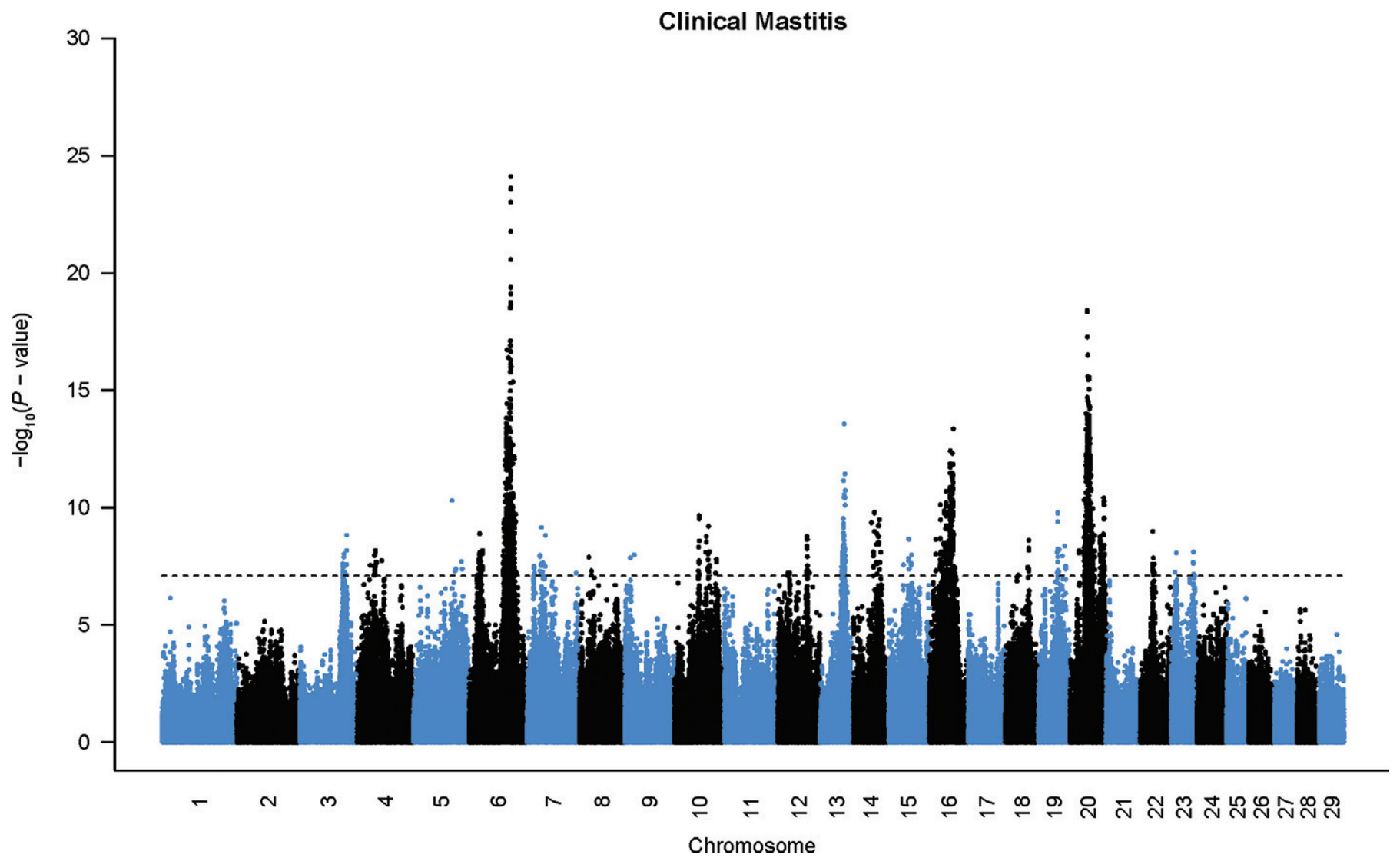

Figure 2. Manhattan plot of a genome-wide association study (GWAS) for clinical mastitis using BovineHD SNP arrays (Illumina Inc., San Diego, CA) in Holstein cattle. The x-axis shows the chromosomes and SNP order within a chromosome. The y-axis shows the $-\log _{10}(P$-value $)$ for each SNP. Color version available in the online PDF.

BTA 5 are presented in Table 3 . Two regions (86.99 and $92.75 \mathrm{Mb}$ ) contained highly significant SNP (Figure 4). The highest $-\log _{10}(P$-value $)$ of 9.89 was observed for the trait clinical mastitis (1) or not (0) between -15 and $50 \mathrm{~d}$ after first calving (CM11) at 92.75 Mb. Although associations with all $5 \mathrm{CM}$ indices were significant after region-wise Bonferroni multiple testing correction, none of the associations with SCC indices were significant after multiple testing correction (Table 3).

The SNP at $92,753,829$ bp was added to the mixed model analysis as a cofactor to examine whether multiple QTL segregate within the targeted BTA 5 region. Although no SNP scored above the region-wise Bonferroni multiple correction threshold, a suggestive peak at $86,998,734 \mathrm{bp}\left[-\log _{10}(P\right.$-value $\left.)=4.6\right]$ was observed for CM (Figure 4). Another suggestive QTL peak at $94,040,980 \mathrm{bp}$, observed for SCC $\left[-\log _{10}(P\right.$-value $)=$ 4.0], was largely unaffected by adding the cofactor to the model (Figure 5). The squared correlation $\left(\mathrm{r}^{2}\right)$ estimates for genotype doses among the region-wise significance markers for this genomic region were high $(>0.60)$ for a very wide region (Supplementary Figure S2, panel A; http://dx.doi.org/10.3168/jds.2014-8141).
This limited our ability to identify a specific causal gene or polymorphism. It is possible that several QTL within the selected region on BTA 5 affect clinical mastitis.

Nordic Red and Jersey Cattle. The most significant SNP associated with CM in Nordic Red and Jersey cattle are presented in Tables 4 and 5 and Supplementary Figures S3 (panel A) and S4 (panel A) (http:// dx.doi.org/10.3168/jds.2014-8141), respectively. The SNP most strongly associated with CM in Nordic Red cattle for the region on BTA 5 was at $88,807,577$ bp $\left[-\log _{10}(P\right.$-value $\left.)=5.66\right]$. The $P$-value was close to the region-wise significance threshold after adjusting for multiple testing $\left[\left(-\log _{10}(P\right.\right.$-value $\left.)=6.04\right]$. In Jersey cattle, the highest peak for CM was at $92,653,455 \mathrm{bp}$ $\left[-\log _{10}(P\right.$-value $\left.)=5.02\right]$. In a meta-analysis of all 3 breeds (Supplementary Figure S5, panel A), the most significant evidence for association was observed for the SNP at $92,753,829 \mathrm{bp}$, which was located in an intergenic region.

\section{Targeted Region on BTA 6}

Holstein Cattle. The strongest genome-wide association signal for CM in Holstein cows was observed 


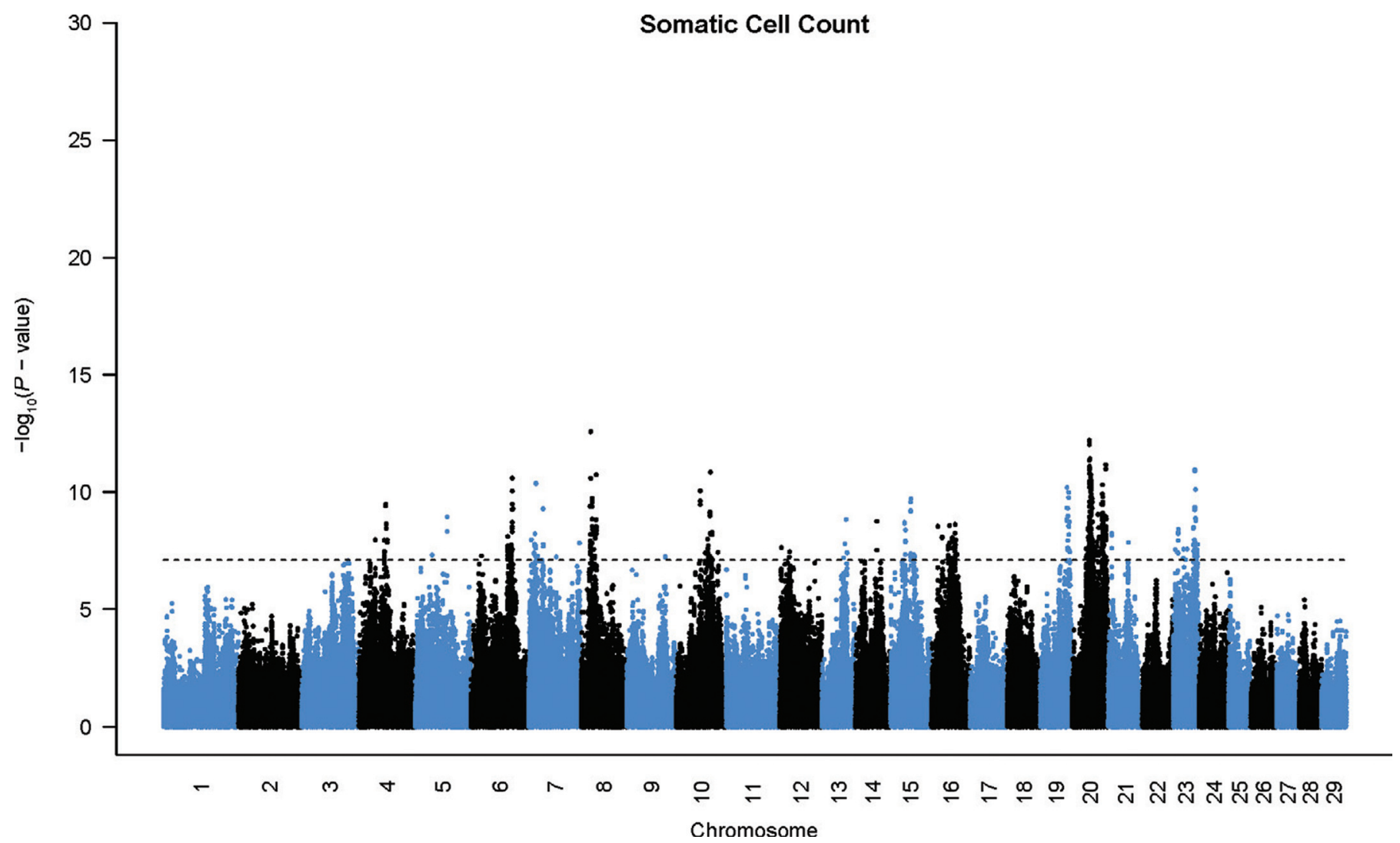

Figure 3. Manhattan plot of a genome-wide association study (GWAS) for SCC using BovineHD SNP arrays (Illumina Inc., San Diego, CA) in Holstein cattle. The $\mathrm{x}$-axis shows the chromosomes and SNP order within the chromosome. The y-axis shows the $-\log _{10}(P$-value $)$ for each SNP. Color version available in the online PDF.

on BTA 6 (Figure 2). The association signal plots for RWAS in CM and SCC for this region are presented in Supplementary Figure S1, panels A and B (http:// dx.doi.org/10.3168/jds.2014-8141), and the most significant SNP for each of the 9 mastitis-related traits are presented in Table 3. The most significant association was observed for CM11 at $88,977,023 \mathrm{bp}$ $\left[-\log _{10}(P\right.$-value $\left.)=38.76\right]$. The SNP at $88,326,504 \mathrm{bp}$ showed the strongest association with all 4 SCC indices. A missense polymorphism in the NPFFR2 gene (rs110326785; 89,059,253 bp) showed a marginally lower $P$-value $\left[-\log _{10}(P\right.$-value $\left.)=37.4\right]$ for $\mathrm{CM} 11 \mathrm{com}$ pared with the highest associated SNP (Supplemental Table S1; http://dx.doi.org/10.3168/jds.2014-8141). However, the $P$-values observed for this SNP with 4 SCC traits were much lower.

The association model was repeated with the most significant SNP (Chr6: 88,977,023 bp) as a cofactor in the mixed model. This SNP was not able to fully absorb the QTL variances (Supplementary Figure S1, panels A and B; http://dx.doi.org/10.3168/jds.2014$8141)$. The highest $-\log _{10}(P$-value $)$ for SCC average in first lactation (SCC1) was at 88,467,803 bp, which was within the SLC4A4 gene. Another significant associa- tion peak was located intragenically at $93,144,678 \mathrm{bp}$. The squared correlation $\left(\mathrm{r}^{2}\right)$ estimates for genotypes among the region-wise significant markers are presented in Supplementary Figure S2, panel B.

The highest associations for CM11 and SCC1 were $141.3 \mathrm{~kb}$ apart. The QTL peaks for SCC remained mostly unchanged when the SNP with the highest association with $\mathrm{CM}$ was included as a cofactor in the model (Supplementary Figure S1, panel B; http:// dx.doi.org/10.3168/jds.2014-8141). Therefore, to examine if multiple causative factors segregate in the BTA 6 region, we performed a bivariate analysis for CM11 and SCC1 and 2 significant SNP [Chr6: 89,059,253 bp, a missense mutation in the NPFFR2 gene $\left(\mathbf{S N P}_{\mathbf{C M}}\right)$ and Chr6: 88,326,504 bp ( SNP $\left.\left._{\mathbf{S C C}}\right)\right]$. The squared correlation of the genotypes between $\mathrm{SNP}_{\mathrm{CM}}$ and $\mathrm{SNP}_{\mathrm{SCC}}$ was 0.19 , indicating that the 2 SNP were not in strong LD. We compared 6 models (Supplemental Table S2; http://dx.doi.org/10.3168/jds.2014-8141) using 2 criteria: the Akaike information criterion $($ AIC) $=-2 \log$ $\mathrm{L}+2 \mathrm{p}$ (Akaike, 1974) and the Bayesian information criterion $(\mathbf{B I C})=-2 \log \mathrm{L}+\mathrm{p} \log \mathrm{N}$ (Schwarz, 1978), where $\mathrm{L}$ is the likelihood of the model fitted, $\mathrm{p}$ is the number of parameters in the model, and $\mathrm{N}$ is the num- 


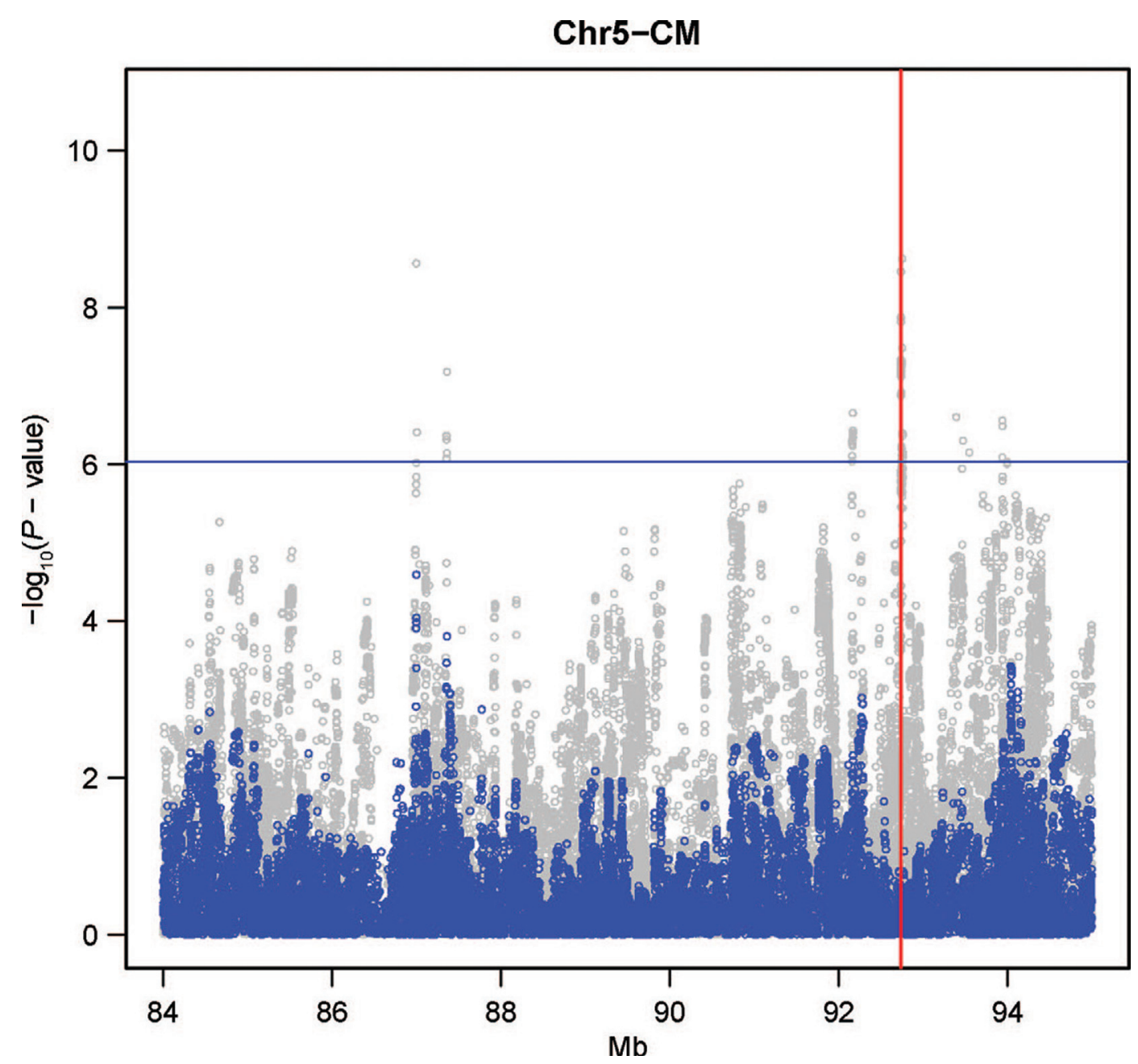

Figure 4. Region-wise association results for clinical mastitis (CM) in Holstein cattle [chromosome (Chr) 5]. Gray circles: liner mixed model association results; blue (black) circles: linear mixed model with highest significant SNP as a cofactor; red vertical line: top SNP position; blue horizontal line: region-wide significance threshold. Color version available in the online PDF.

ber of data points. The smaller the AIC/BIC value, the better the model is. The model for $\mathrm{SNP}_{\mathrm{CM}}$ and $\mathrm{SNP}_{\mathrm{SCC}}$ affecting CM11 and $\mathrm{SNP}_{\mathrm{SCC}}$ affecting SCC1 had the lowest AIC and BIC values (Supplemental Table S2), providing strong evidence that more than one causal factor affected CM and SCC in the BTA 6 QTL region. It further indicated that $\mathrm{SNP}_{\mathrm{CM}}$ affected only CM11, whereas $\mathrm{SNP}_{\mathrm{SCC}}$ affected CM11 and SCC1. The phenotypes used for this study were breeding values from a multi-trait model. The significance association observed for $\mathrm{SNP}_{\mathrm{CM}}$ on $\mathrm{SCC} 1$ in the single-trait analysis may be due to combined effects of CM on SCC.

Nordic Red and Jersey Cattle. The QTL peak on BTA 6 in Nordic Red cattle was at 88.6 to $89.1 \mathrm{Mb}$, and the highest peak was found at Chr6: 88,723,742 bp $\left[-\log _{10}(P\right.$-value $)=26.03$; Supplementary Figure S3, panel B (http://dx.doi.org/10.3168/jds.2014-8141) and Table 4]. No significant associations existed within the targeted region on BTA 6 in Jersey cattle (Supple- mentary Figure S4, panel B). The strongest association signal found in both breeds in meta-analyses was at 88.92 to $89.05 \mathrm{Mb}$, and the most significant SNP within that region was located at Chr6: 88,977,023 bp (Supplementary Figure S5, panel B). Two genes, neuropeptide FF receptor 2 (NPFFR2; 89,052,210 to 89,059,348 bp) and vitamin D-binding protein precursor $(\boldsymbol{G C}$; $88,695,940$ to $88,739,180 \mathrm{bp}$ ) are located close to the most significantly associated SNP. Figure 6 shows how the haplotypes around the 2 genes (NPFFR2 and $G C$ ) extended over a long range in Nordic Red cattle. The spread of LD limited our ability to identify one particular gene or polymorphism as the casual factor.

\section{Targeted Region on BTA 13}

Holstein Cattle. The most significant SNP for each of the 9 mastitis-related traits for the targeted region on BTA 13 are presented in Table 3. The as- 


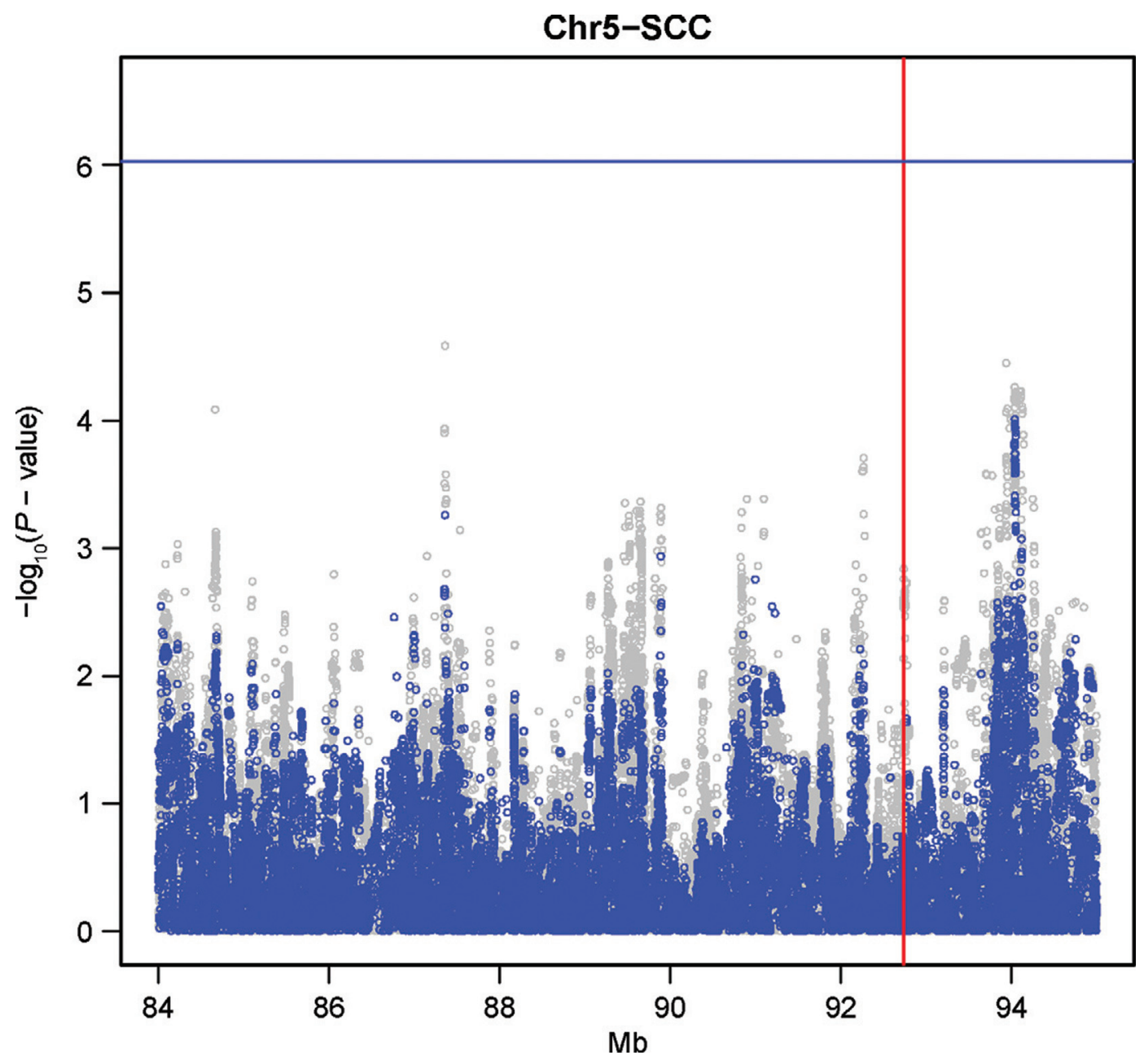

Figure 5. Region-wide association results for SCC for Holstein cattle [chromosome (Chr) 5]. Gray circles: liner mixed model association results; blue (black) circles: linear mixed model with highest significant SNP as a cofactor; red vertical line: top SNP position; blue horizontal line: region-wise significance threshold. Color version available in the online PDF.

sociation signal plots for CM and SCC for this region are presented in Supplementary Figure S1, panels C and D (http://dx.doi.org/10.3168/jds.2014-8141). The most significant SNP for traits CM11, CM (1) or not (0) between 51 and $305 \mathrm{~d}$ after first calving (CM12), $\mathrm{CM}$, and SCC1 were located around $57.60 \mathrm{Mb}$, and the most significant SNP for the traits CM (1) or not (0) between -15 and $150 \mathrm{~d}$ after second calving (CM2) and CM (1) or not (0) between -15 and $150 \mathrm{~d}$ after third calving (CM3) were found around $59.58 \mathrm{Mb}$. The most significant SNP for the logarithm of SCC average in second lactation (SCC2), logarithm of SCC average in third lactation (SCC3), and SCC were at $60.62 \mathrm{Mb}$.

After the SNP at $57,608,628$ bp was included as a cofactor in the mixed-model analysis, a few suggestive peaks remained. However, no SNP crossed the significance threshold (Supplementary Figure S1, panels
C and D; http://dx.doi.org/10.3168/jds.2014-8141). Linkage disequilibrium among the significant SNP did not spread across a large region (Supplementary Figure S2, panel C).

Nordic Red and Jersey Cattle. The most significant SNP for $\mathrm{CM}$ was at $58.28 \mathrm{Mb}\left[-\log _{10}(P\right.$-value $)=$ $9.04]$ in Nordic Red and at $61.98 \mathrm{Mb}\left[-\log _{10}(P\right.$-value $)=$ 5.49 in Jersey cattle [Supplemental Figures S3 (panel C) and S4 (panel C); http://dx.doi.org/10.3168/jds.20148141]. The most significant SNP from the meta-analysis was located at 59,711,506 bp (Supplementary Figure S5, panel C), which was close to a known microRNA $(59,724,647$ to $59,724,754 \mathrm{bp})$. The second best region on BTA 13, according to the meta-analysis, was located at 57.60 to $57.85 \mathrm{Mb}$. This region was also significant in within-breed analyses for Holstein and Nordic Red cattle. It includes 2 genes, EDN3 and ZNF831. 
Table 3. The most significant SNP for 9 mastitis traits in 6 target regions ${ }^{1}$

\begin{tabular}{|c|c|c|c|c|c|c|c|c|c|}
\hline BTA & Trait $^{2}$ & $\begin{array}{l}\text { Top associated } \\
\text { SNP }^{3}\end{array}$ & rs-ID & MAF & Effect & $\mathrm{SE}$ & $-\log _{10}(P \text {-value })^{4}$ & Alleles & $\begin{array}{c}\text { Allele } \\
\text { increasing } \\
\text { mastitis } \\
\text { resistance }\end{array}$ \\
\hline & CM12 & Chr5: 86998734 & rs134318301 & 0.487 & -1.14 & 0.20 & 7.80 & $\mathrm{G} / \mathrm{A}$ & $\mathrm{G}$ \\
\hline & CM2 & Chr5:87360522 & rs135193997 & 0.222 & 14.06 & 2.58 & 7.26 & $\mathrm{~A} / \mathrm{T}$ & $\mathrm{T}$ \\
\hline & CM3 & Chr5: 93941017 & rs136218697 & 0.254 & -1.22 & 0.22 & 7.40 & $\mathrm{~A} / \mathrm{G}$ & $\mathrm{A}$ \\
\hline & $\mathrm{CM}$ & Chr5:92753829 & rs382053320 & 0.204 & 1.87 & 0.31 & 8.61 & $\mathrm{~A}^{\prime} / \mathrm{G}$ & $\mathrm{G}$ \\
\hline & SCC3 & Chr5:89528205 & $\mathrm{NA}^{5}$ & 0.020 & 13.34 & 2.95 & 5.22 & $\mathrm{G} / \mathrm{T}$ & $\mathrm{T}$ \\
\hline & SCC & Chr5:87360522 & rs135193997 & 0.222 & 10.76 & 2.56 & 4.58 & $\mathrm{~A} / \mathrm{T}$ & $\mathrm{T}$ \\
\hline \multirow[t]{4}{*}{6} & CM11 & Chr6:88977023 & rs211282601 & 0.432 & -2.80 & 0.21 & 38.76 & $\mathrm{C} / \mathrm{T}$ & $\mathrm{C}$ \\
\hline & CM12 & Chr6:88612186 & rs110484192 & 0.403 & -2.77 & 0.26 & 25.27 & $\mathrm{G} / \mathrm{T}$ & G \\
\hline & CM2 & Chr6:88610743 & NA & 0.169 & -5.95 & 0.58 & 23.84 & $\mathrm{~T} / \mathrm{A}$ & $\mathrm{T}$ \\
\hline & CM3 & Chr6:88977023 & rs211282601 & 0.432 & -2.45 & 0.21 & 30.21 & $\mathrm{C} / \mathrm{T}$ & $\mathrm{C}$ \\
\hline \multirow[t]{9}{*}{13} & CM11 & Chr13:57608336 & NA & 0.072 & -8.13 & 1.03 & 14.46 & $\mathrm{~A} / \mathrm{C}$ & $\mathrm{A}$ \\
\hline & CM12 & Chr13:57608354 & rs136565195 & 0.294 & -1.79 & 0.25 & 12.00 & $\mathrm{~A} / \mathrm{G}$ & $\mathrm{A}$ \\
\hline & CM2 & Chr13:59584651 & NA & 0.234 & -6.43 & 0.90 & 12.02 & $\mathrm{~T} / \mathrm{G}$ & $\mathrm{T}$ \\
\hline & CM3 & Chr13:59584651 & NA & 0.234 & -6.73 & 0.86 & 14.32 & $\mathrm{~T} / \mathrm{G}$ & $\mathrm{T}$ \\
\hline & $\mathrm{CM}$ & Chr13:57608628 & rs133732637 & 0.305 & -1.91 & 0.24 & 15.07 & $\mathrm{~A} / \mathrm{G}$ & $\mathrm{A}$ \\
\hline & SCC1 & Chr13:57608354 & rs136565195 & 0.294 & -1.62 & 0.26 & 9.35 & $\mathrm{~A} / \mathrm{G}$ & $\mathrm{A}$ \\
\hline & SCC2 & Chr13:60621602 & NA & 0.014 & -29.84 & 4.51 & 10.39 & $\mathrm{~A} / \mathrm{G}$ & $\mathrm{A}$ \\
\hline & SCC3 & Chr13:60621602 & NA & 0.014 & -31.43 & 4.68 & 10.69 & $\mathrm{~A} / \mathrm{G}$ & $\mathrm{A}$ \\
\hline & SCC & Chr13:60621602 & NA & 0.014 & -28.31 & 4.29 & 10.34 & $\mathrm{~A} / \mathrm{G}$ & $\mathrm{A}$ \\
\hline \multirow[t]{5}{*}{16} & CM11 & Chr16:50529178 & rs109477998 & 0.019 & 28.70 & 3.63 & 14.51 & $\mathrm{G} / \mathrm{A}$ & $\mathrm{A}$ \\
\hline & CM12 & Chr16:49054912 & rs211089604 & 0.282 & 1.50 & 0.25 & 8.72 & $\mathrm{C} / \mathrm{T}$ & $\mathrm{T}$ \\
\hline & CM2 & Chr16:49054912 & rs211089604 & 0.282 & 1.42 & 0.26 & 7.34 & $\mathrm{C} / \mathrm{T}$ & $\mathrm{T}$ \\
\hline & CM3 & Chr16:54246279 & rs207559736 & 0.241 & 1.31 & 0.23 & 8.01 & $\mathrm{C} / \mathrm{A}$ & $\mathrm{A}$ \\
\hline & $\mathrm{CM}$ & Chr16:50532600 & rs110021548 & 0.306 & 1.66 & 0.25 & 10.49 & $\mathrm{C} / \mathrm{A}$ & $\mathrm{A}$ \\
\hline & SCC1 & Chr19:55296191 & rs136372044 & 0.380 & -1.63 & 0.25 & 9.90 & $\mathrm{~T} / \mathrm{G}$ & $\mathrm{T}$ \\
\hline & $\mathrm{SCC} 2$ & Chr19:55296191 & rs136372044 & 0.380 & -1.79 & 0.27 & 10.71 & $\mathrm{~T} / \mathrm{G}$ & $\mathrm{T}$ \\
\hline & SCC3 & Chr19:55296191 & rs136372044 & 0.380 & -1.88 & 0.28 & 10.90 & $\mathrm{~T} / \mathrm{G}$ & $\mathrm{T}$ \\
\hline & SCC & Chr19:55296191 & rs136372044 & 0.380 & -1.63 & 0.25 & 10.03 & $\mathrm{~T} / \mathrm{G}$ & $\mathrm{T}$ \\
\hline \multirow[t]{9}{*}{20} & CM11 & Chr20:34269660 & rs378477749 & 0.457 & 2.20 & 0.30 & 12.81 & $\mathrm{~T} / \mathrm{C}$ & $\mathrm{C}$ \\
\hline & CM12 & Chr20:35965955 & rs210536202 & 0.203 & 2.18 & 0.28 & 14.14 & $\mathrm{G} / \mathrm{A}$ & $\mathrm{A}$ \\
\hline & CM2 & Chr20:35965955 & rs210536202 & 0.203 & 2.34 & 0.29 & 15.24 & $\mathrm{G} / \mathrm{A}$ & $\mathrm{A}$ \\
\hline & CM3 & Chr20:35914181 & rs109032146 & 0.241 & -1.87 & 0.24 & 13.59 & $\mathrm{G} / \mathrm{A}$ & G \\
\hline & $\mathrm{CM}$ & Chr20:35965955 & rs210536202 & 0.203 & 2.10 & 0.27 & 14.17 & $\mathrm{G} / \mathrm{A}$ & $\mathrm{A}$ \\
\hline & SCC1 & Chr20:35969130 & rs210635121 & 0.315 & -1.98 & 0.27 & 12.43 & $\mathrm{G} / \mathrm{A}$ & $\mathrm{G}$ \\
\hline & $\mathrm{SCC} 2$ & Chr20:35865606 & rs211644570 & 0.328 & -1.86 & 0.25 & 12.98 & $\mathrm{G} / \mathrm{T}$ & $\mathrm{G}$ \\
\hline & SCC3 & Chr20:35914086 & NA & 0.086 & -22.33 & 2.94 & 13.45 & $\mathrm{~A} / \mathrm{C}$ & $\mathrm{A}$ \\
\hline & SCC & Chr20:35543794 & rs209723131 & 0.323 & 1.86 & 0.25 & 12.96 & $\mathrm{~A} / \mathrm{G}$ & $\mathrm{G}$ \\
\hline
\end{tabular}

${ }^{1}$ rs-ID = reference SNP identification; MAF = minor allele frequency; effect = allele substitution effect for the SNP; SE $=$ SE for the SNP effect. ${ }^{2}$ The trait indices are defined in Table 1; the first number after CM or SCC is for the lactation number and the second number (if included) is for the part of lactation.

${ }^{3} \mathrm{Chr}=$ chromosome.

${ }^{4}$ The Bonferroni-corrected significant thresholds at $5 \%$ were $6.04,5.92,5.58,5.74,5.51$, and 5.60 for BTA5, 6, 13, 16, 19, and 20, respectively. ${ }^{5} \mathrm{NA}=$ not available. 
Table 4. The most significant SNP associated with clinical mastitis in Nordic Red cattle ${ }^{1}$

\begin{tabular}{llllrrr}
\hline BTA & SNP $^{2}$ & rs-ID & MAF & Effect & SE & $-\log _{10}(P$-value $)$ \\
\hline 5 & Chr5:88807577 & rs209323908 & 0.253 & -1.571 & 0.331 & 5.662 \\
6 & Chr6:88723742 & NA $^{3}$ & 0.434 & -2.678 & 0.248 & 26.032 \\
13 & Chr13:58281235 & rs133942526 & 0.177 & -2.052 & 0.335 & 9.035 \\
16 & Chr16:53648796 & rs378552666 & 0.034 & -3.291 & 0.816 & 4.25 \\
19 & Chr19:53755088 & rs137394508 & 0.304 & 1.353 & 0.279 & 5.889 \\
20 & Chr20:37623880 & rs379484142 & 0.173 & 1.588 & 0.338 & 5.558 \\
\hline
\end{tabular}

${ }^{1}$ rs-ID = reference SNP identification; MAF = minor allele frequency; effect = allele substitution effect for the SNP.

${ }^{2} \mathrm{Chr}=$ chromosome.

${ }^{3} \mathrm{NA}=$ not available.

\section{Targeted Region on BTA 16}

Holstein Cattle. The most significant SNP for each of the 9 mastitis-related traits are presented in Table 3. The association signal plots for CM and SCC for this region are presented in Supplementary Figure S1, panels E and F (http://dx.doi.org/10.3168/jds.2014-8141). The highest $-\log _{10}(P$-values $)$ were observed at 50.53 $\mathrm{Mb}$ for CM11 and CM, at $49.05 \mathrm{Mb}$ for CM12 and $\mathrm{CM} 2$, and between 53.8 and $54.2 \mathrm{Mb}$ for $\mathrm{CM} 3, \mathrm{SCC} 2$, SCC3, and SCC.

The SNP at position 50,529,178 bp was fitted as a cofactor in the mixed-model analysis. No SNP remained significant for CM, but a few suggestive peaks were left for SCC (Supplementary Figure S1, panel F; http:// dx.doi.org/10.3168/jds.2014-8141). This indicated that multiple genes in the region affect CM or SCC, or both. Despite blocks of high correlation, strong LD was not spread across the entire targeted region (Supplementary Figure S2, panel D). This may account for the association peaks that remained after the cofactor was fitted in the mixed model.

Nordic Red and Jersey Cattle. Quantitative trait loci for $\mathrm{CM}$ at 51.5 and $53.6 \mathrm{Mb}$ were detected in Nordic Red cattle, but they did not exceed the region-wise significance threshold (Supplementary Figure S3, panel D; http://dx.doi.org/10.3168/jds.2014-8141). The most significant SNP in Jersey was at 50,349,772 bp [$\log _{10}(P$-value $)=8.23$; Table 5 ; Supplementary Figure S4, panel D]. Another region, $52.7 \mathrm{MB}\left[-\log _{10}(P\right.$-value $)$ $=7.27$ ], was identified in Jersey cattle, although a meta- analysis across the 3 breeds was unable to highlight any particular regions (Supplementary Figure S5, panel D).

\section{Targeted Region on BTA 19}

Holstein Cattle. The most significant SNP for each of the 9 mastitis related traits for the targeted region of BTA 19 are presented in Table 3. The association signal plots for $\mathrm{CM}$ and SCC for this region are presented in Supplementary Figure S1, panels G and H (http:// dx.doi.org/10.3168/jds.2014-8141). Interestingly, this region showed stronger association signals for SCC traits than for CM traits.

The SNP located at 55,296,191 bp was used as cofactor because of its effect on SCC. However, some suggestive peaks for SCC were left after fitting this cofactor, including peaks at $57,855,321$ bp $\left[-\log _{10}(P-\right.$ value $)=4.52]$ and $57,162,671$ bp $\left[-\log _{10}(P\right.$-value $)$ $=3.89$. These 2 peaks and an additional peak at $55,459,927$ bp $\left[-\log _{10}(P\right.$-value $\left.)=3.44\right]$ were observed for CM. Strong LD extended across the whole region (Supplementary Figure S2, panel E; http://dx.doi. org/10.3168/jds.2014-8141). Therefore, it was not possible to conclude whether one or multiple variants were responsible for the association signal observed on BTA 19. However, the suggestive QTL peaks that remained after inclusion of the cofactor indicated the possible presence of multiple causal factors affecting CM and SCC.

Nordic Red and Jersey Cattle. The most significant SNP in Nordic Red cattle was Chr19: 53,755,088 bp

Table 5. The most significant SNP associated with clinical mastitis in Danish Jersey cattle ${ }^{1}$

\begin{tabular}{lllllll}
\hline BTA & SNP $^{2}$ & rs-ID & MAF & Effect & SE & $-\log _{10}(P$-value $)$ \\
\hline 5 & Chr5:92653455 & rs137721018 & 0.223 & -1.822 & 0.41 & 5.022 \\
6 & Chr6:95099773 & rs110862298 & 0.412 & -1.542 & 0.372 & 4.441 \\
13 & Chr13:61987286 & rs41706383 & 0.419 & -1.812 & 0.387 & 5.487 \\
16 & Chr16:50349772 & rs136284597 & 0.410 & -2.374 & 0.405 & 8.227 \\
19 & Chr19:57742139 & rs383319945 & 0.414 & 1.277 & 0.377 & 3.134 \\
20 & Chr20:39666328 & rs210713076 & 0.223 & 2.161 & 0.423 & 6.407 \\
\hline
\end{tabular}

${ }^{1}$ rs-ID = reference SNP identification; MAF = minor allele frequency; effect = allele substitution effect for the SNP.

${ }^{2} \mathrm{Chr}=$ chromosome. 
Chr-6-89MB

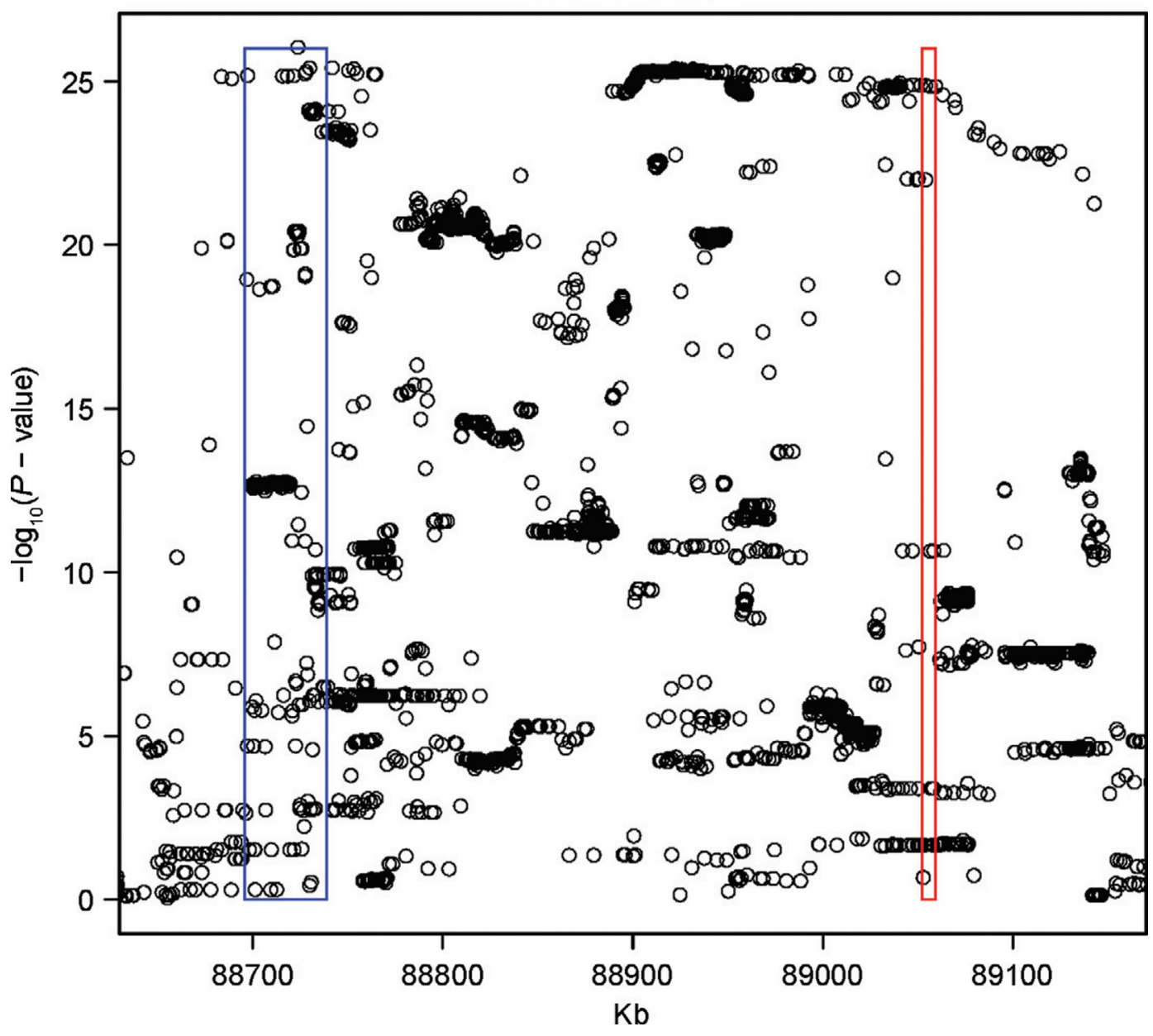

Figure 6. Haplotype structure at the highest association region for clinical mastitis on BTA 6 in Nordic Red cattle. The locations for neuropeptide FF receptor 2 (NPFFR2; red; on right) and vitamin D-binding protein precursor ( $G C$; blue; on left) genes are marked. Chr $=$ chromosome. Color version available in the online PDF.

$\left[-\log _{10}(P\right.$-value $)=5.89$; Table 4 ; Supplementary Figure S3, panel E (http://dx.doi.org/10.3168/jds.2014-8141)]. This region did not contain any significant associations in Jersey cattle (Supplementary Figure S4, panel E). Meta-analyses across 3 breeds indicated 2 QTL peaks (Supplementary Figure S5, panel E). One was located at 56,529,610 bp, which included the SAP30BP gene, and the second was located at $55,466,436 \mathrm{bp}$ close to SCARNA16.

\section{Targeted Region on BTA 20}

Holstein Cattle. The most significant SNP for each of the 9 mastitis-related traits for the targeted region on BTA 20 are presented in Table 3. The association signal plots for $\mathrm{CM}$ and SCC for this region are presented in Supplementary Figure S1, panels I and J (http://dx.doi.org/10.3168/jds.2014-8141). The most significant SNP for the 9 traits were located between 35.54 and $35.97 \mathrm{Mb}$, except for CM11, which was located at $34.27 \mathrm{Mb}$.

When the SNP at $35,965,955$ bp was used as a cofactor in the model, no other SNP crossed the region-wise significance threshold. High LD between polymorphisms existed across the whole region (Supplementary Figure S3, panel F; http://dx.doi.org/10.3168/jds.2014-8141), suggesting that a cofactor may have absorbed the effects of additional QTL.

Nordic Red and Jersey Cattle. The meta-analysis across 3 breeds could not clearly mark any regions containing QTL (Supplementary Figure S5, panel F; http://dx.doi.org/10.3168/jds.2014-8141). The most strongly associated SNP from the meta-analysis was at $33,398,781 \mathrm{bp}$. The $-\log _{10}(P$-values $)$ for Holstein, Nordic Red, and Jersey cattle were 11.48, 3.20, and 3.34 , respectively, with MAF ranging from 0.34 to 0.45 . 
This SNP was located close to the $c 6$ gene, which may indicate that $c 6$ is a positional candidate gene on BTA 20. Evidence also existed of marker-trait association around $35.96 \mathrm{Mb}$, which includes the LIFR gene, which is involved in the acute-phase response and is expressed in the mammary gland.

\section{QTL for Milk Production Traits in the Targeted Regions}

Clinical mastitis has unfavorable genetic correlations with milk production traits (Lund et al., 1999; Heringstad et al., 2005). Therefore, 3 milk production traits (milk yield, fat yield, and protein yield) were analyzed to determine whether mastitis QTL cosegregated with milk trait QTL (Table 6).

A strong association with SNP for milk production traits was observed in the mastitis QTL region on BTA 5. Association signals were observed for fat, milk, and protein $\left[-\log _{10}(P\right.$-values were $27.02,24.29$, and 11.89 , respectively]. The most strongly associated SNP for fat (rs209372883) was located in an intron within the microsomal glutathione S-transferase 1 (MGST1) gene; MGST1 belongs to the membrane-associated proteins in eicosanoid and glutathione metabolism family of proteins and contains an $\mathrm{FA} /$ phospholipid substrate binding site (Busenlehner et al., 2007). The product of MGST1 is predominantly localized to the outer mitochondrial membrane and the endoplasmic reticulum, the site of lipid synthesis, and it is thought to protect membranes from oxidative stress (Johansson et al., 2010). It is capable of catalyzing glutathione-dependent reduction of certain lipid hydroperoxides, such as FA hydroperoxides (Mosialou et al., 1995). These factors combined indicate that MGST1 is a good candidate gene for the fat QTL localized to BTA 5.

Genome-wide significant associations for protein and milk were observed in the selected region on BTA 6 . The most significant SNP for protein and milk were located at 89.52 and $88.43 \mathrm{Mb}$, respectively. $\kappa$-Casein: casoxin-C, casoxin-6, casoxin-A, casoxin-B, casoplatelin (CSN3) is located at $87,378,398$ to $87,392,750 \mathrm{bp}$, and $\beta$-CN casoparan antioxidant peptide casohypotensin (CSN2) is located at $87,179,502$ to $87,188,025$ bp on BTA 6. Unexpectedly, the SNP most significantly associated with the protein index was not found within the casein genes. The region (87-89 Mb) on BTA 6 harbors multiple genes that may affect milk production and clinical mastitis; therefore, the highest significant SNP observed could be due to LD with multiple causative polymorphisms.

On BTA 13 , the highest $-\log _{10}(P$-value $)$ was 8.19 for the fat index at $61.29 \mathrm{Mb}$ but no evidence for QTL for milk and protein was detected. Significant associations for all 3 milk production traits were observed on BTA 20 . The highest $-\log _{10}(P$-value $)$ for fat, protein, and milk indices were 19.61 (at $32.66 \mathrm{Mb}$ ), 9.04 (at 33.98 $\mathrm{Mb}$ ), and 12.50 (at $33.08 \mathrm{Mb}$ ), respectively. No significant associations with the 3 milk production traits were observed in the mastitis QTL regions on BTA 16 and 19.

\section{Functionally Important Polymorphisms}

A total of $25 \mathrm{SNP}$ were selected based on their location in the genome and their annotations (Table 7).

Table 6. The most significant SNP associated with 3 milk production traits in Holstein ${ }^{1}$

\begin{tabular}{|c|c|c|c|c|c|c|c|}
\hline BTA & Trait & Top associated $\mathrm{SNP}^{2}$ & rs-ID & MAF & Effect & $\mathrm{SE}$ & $-\log _{10}(P$-value $)$ \\
\hline 5 & Fat & Chr5:93948357 & rs209372883 & 0.34 & -2.79 & 0.25 & 27.02 \\
\hline 5 & Protein & Chr5:93943469 & rs208300663 & 0.44 & 1.73 & 0.24 & 11.89 \\
\hline 5 & Milk & Chr5:93945655 & rs134637616 & 0.39 & 2.76 & 0.27 & 24.29 \\
\hline 6 & Fat & Chr6:88958680 & rs110524368 & 0.26 & 1.39 & 0.26 & 6.96 \\
\hline 6 & Protein & Chr6:89524543 & rs133700571 & 0.14 & 2.74 & 0.35 & 14.14 \\
\hline 6 & Milk & Chr6:88441546 & rs42250122 & 0.45 & 1.92 & 0.25 & 13.61 \\
\hline 13 & Fat & Chr13:61286466 & rs132846509 & 0.19 & -1.65 & 0.28 & 8.19 \\
\hline 13 & Protein & Chr13:60617711 & rs109236897 & 0.15 & 1.60 & 0.34 & 5.71 \\
\hline 13 & Milk & Chr13:58610384 & rs208416430 & 0.19 & 1.70 & 0.32 & 6.77 \\
\hline 16 & Fat & Chr16:48497798 & rs41814122 & 0.15 & 1.17 & 0.32 & 3.62 \\
\hline 16 & Protein & Chr16:49822386 & rs208210443 & 0.28 & 1.58 & 0.28 & 7.94 \\
\hline 16 & Milk & Chr16:48030340 & $\mathrm{NA}^{3}$ & 0.32 & 1.46 & 0.27 & 7.43 \\
\hline 19 & Fat & Chr19:55072685 & rs385314842 & 0.03 & -2.31 & 0.59 & 4.08 \\
\hline 19 & Protein & Chr19:55011041 & rs137486232 & 0.35 & -1.24 & 0.26 & 5.69 \\
\hline 19 & Milk & Chr19:55115956 & NA & 0.38 & -1.18 & 0.26 & 5.22 \\
\hline 20 & Fat & Chr20:32663326 & rs109827679 & 0.30 & -2.26 & 0.24 & 19.61 \\
\hline 20 & Protein & Chr20:32976382 & rs41577202 & 0.06 & 3.02 & 0.49 & 9.04 \\
\hline 20 & Milk & Chr20:33079694 & rs210194122 & 0.11 & 2.86 & 0.39 & 12.50 \\
\hline
\end{tabular}

${ }^{1}$ rs-ID = reference SNP identification; MAF = minor allele frequency; effect = allele substitution effect for the SNP.

${ }^{2} \mathrm{Chr}=$ chromosome.

${ }^{3} \mathrm{NA}=$ not available. 
Among those, 10 were intergenic. Association results with CM and SCC in Holstein cattle were available for 22 SNP (Supplemental Table S3; http://dx.doi. org/10.3168/jds.2014-8141). The association strengths for most of the SNP, except those on BTA 6, were lower than associations observed for the respective targeted regions.

\section{Candidate Genes Within the Targeted Region}

On a genome-wide scale, the most significant SNP associated with CM were located on BTA 6 in the 88 to $90 \mathrm{Mb}$ region, which harbors the $G C$ and the NPFFR2 genes. Both genes are good candidates; however, due to near complete LD in this narrow region, it was impossible to pinpoint the causative gene with association data alone. The $G C$ gene encodes Gc-globulin, which transports and delivers vitamin D to target cells, such as monocytes, leading to synthesis of cathelicidin antimicrobial peptides (Hewison, 2011). Moreover, Gcglobulin functions as a potent macrophage-activating factor, which greatly enhances phagocytic activity in macrophages (Yamamoto and Homma, 1991). Neuropeptide FF receptors 1 and 2 are membrane proteins activated by neuropeptides NPAF and NPFF, which belong to the RFamide family of peptides (Jhamandas and Goncharuk, 2013). It has been shown that NPFF neuropeptides reduce production of nitric oxide in macrophages and exhibit antiinflammatory activity in a mouse model (Sun et al., 2013). Furthermore, T lymphocytes have binding sites for NPFF, and data indicate that NPFF can modulate $\mathrm{T}$ lymphocyte proliferation to fine tune an immune response (Lecron et al., 1992; Minault et al., 1995).

The association signal plots for BTA 5, 13 16, 19, and 20 showed much wider peaks with lower $-\log _{10}(P$-values) compared with BTA 6. On BTA 5, 2 regions harbored significant SNP. The SOX5 gene, which encodes a transcription factor primarily involved in chondrogenic differentiation (Ikeda et al., 2005) and development of neuronal cell types, is located in the first peak at 86.99 Mb (Kwan et al., 2008; Lai et al., 2008), but it has no obvious immune-related functions. The second peak at $92.75 \mathrm{Mb}$ lacks any annotated genes. The gene nearest to the SNP with the highest evidence for association in meta-analyses across 3 breeds was the Ras-related and estrogen-regulated growth inhibitor-like protein (RERGL; 92,432,331-92,442,968 bp). Little or no functional information about this gene exists in the literature. However, the Ras family of small guanosine triphosphatases (GTPase) is a group of more than 150 proteins that function in diverse biological processes, including immunity and inflammation (Johnson and Chen, 2012).

Table 7. Functionally important SNP identified using SIFT (Ng and Henikoff, 2001) and PolyPhen-2 software (Adzhubei et al., 2010)

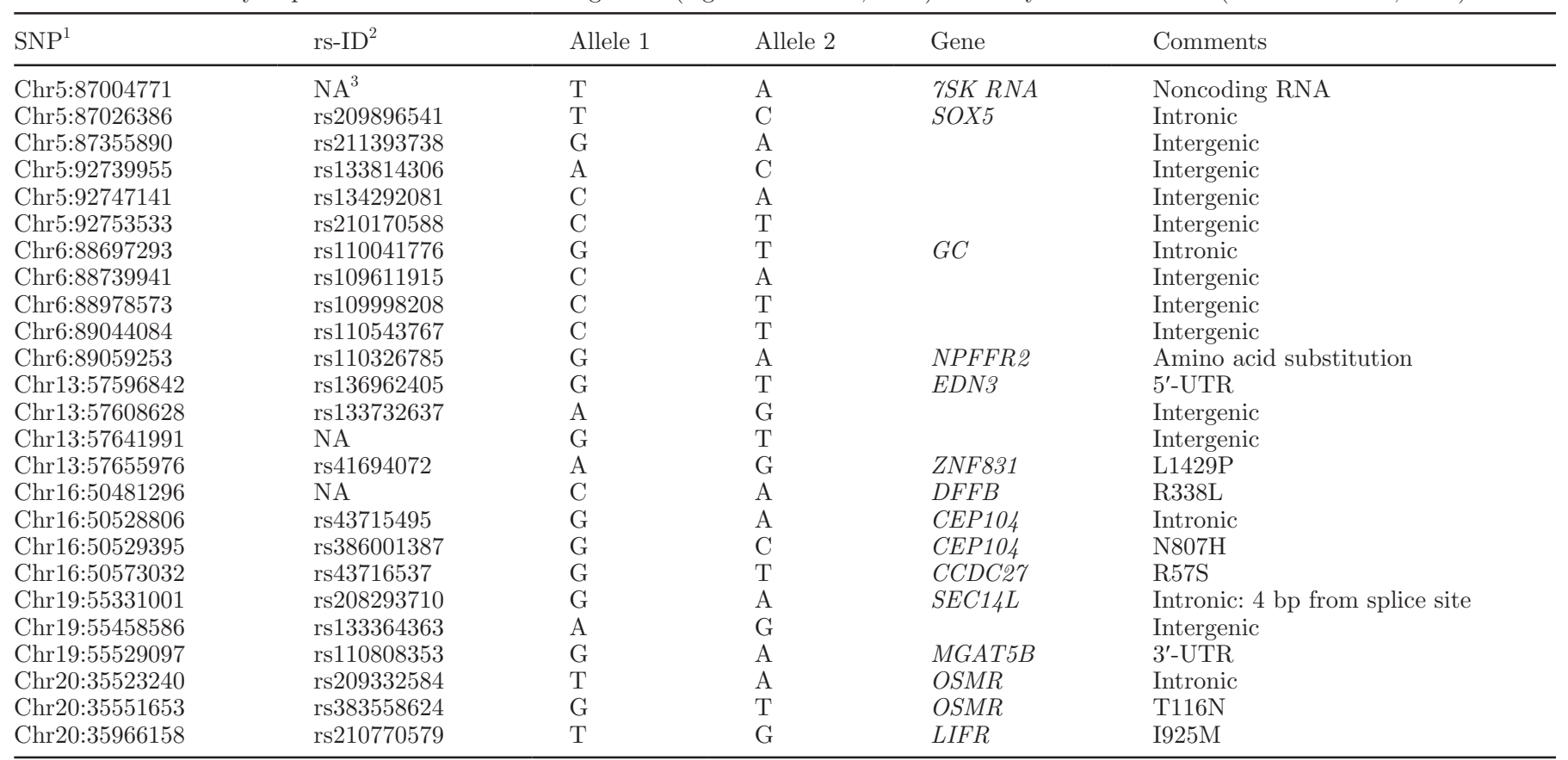

${ }^{1} \mathrm{Chr}=$ chromosome.

${ }^{2}$ rs-ID = reference SNP identification.

${ }^{3} \mathrm{NA}=$ not available. 
Somatic cell count showed significant association with SNP on BTA 19, with the highest value at $55,296,191 \mathrm{bp}$. The closest annotated gene to this position is endonuclease V. The cellular functions of this ribonuclease are poorly defined, but a role in removing inosine-containing RNA, which may have adverse effects in living cells, has been demonstrated (Morita et al., 2013). The meta-analyses across breeds indicated 2 QTL peaks, one at 55,466,436 bp and another at $56,529,610 \mathrm{bp}$, in a region without genes with obvious immune-related functions. In Holstein cattle, the mastitis resistance index had its most significant value at position $55,615,219 \mathrm{bp}$, close to the regulatory associated protein of the mTOR complex 1 gene. The gene $m T O R C 1$ is involved in regulatory T-cell function, and deletion of RPTOR in mice results in severe inflammatory diseases (Zeng et al., 2013).

The most significant SNP on BTA 20 were located in close proximity to the LIFR gene, which encodes the $\alpha$ subunit of the leukemia inhibitory factor receptor. Leukemia inhibitory factor is a pleiotropic cytokine with effects on multiple tissues and cells. Its activities include maintenance of hematopoietic stem cells in spleen and bone marrow (Escary et al., 1993), modulation of inflammatory responses (Linker et al., 2008), and stimulation of acute-phase protein synthesis in hepatocytes (Baumann and Wong, 1989). Among 2 missense SNP at $35,965,955$ and $35,965,956 \mathrm{bp}$, the first one showed strong association with all 9 traits analyzed in Holstein cattle. The meta-analysis across 3 breeds could not clearly mark a particular region for the QTL. The most strongly associated SNP from the meta-analysis was at $33,398,781 \mathrm{bp}\left[-\log _{10}(P\right.$-values $)$ for individual breeds: Holstein: 11.48, Nordic Red: 3.20, and Jersey: 3.34] and MAF ranging from 0.34 to 0.45 . The peak is close to the gene encoding complement component, which is part of the membrane attack complex that disrupts microbial membranes, leading to cell lysis and death (Ricklin et al., 2010).

\section{Previously Reported Mastitis QTL from Target Regions}

Sahana et al. (2013) carried out an association study using the 50K SNP chip in the Nordic Holstein population. An increased sample size (from approximately 2,000 to 5,000 ) and marker density [50K to 777,000 $(777 \mathrm{~K})]$ resulted in identification of new associations along with increased strength of associations in the current study (Figures 2 and 3 ).

Several other studies have identified genetic associations for mastitis-related traits on the same chromosomes as this study. Several studies have reported associations with SCC/CM with genomic region on BTA6 similar to those in the present study; for example, in US Holstein (Cole et al. 2011), German Holstein (AbdelShafy et al., 2014), and Norwegian Red cattle (Nilsen et al., 2009; Sodeland et al., 2011). Meredith et al. (2013) identified associations on BTA 13 and BTA 20, similar to the current study. In addition, Sodeland et al. (2011) reported a wide region on BTA 20 in Norwegian Red cattle, supporting the results of the current study. However, most of the previously identified associations were located in different regions on the chromosomes. This was true for BTA 5 (Cole et al., 2011; Meredith et al., 2013), BTA 6 (Meredith et al., 2013), BTA 13 (Cole et al., 2011), BTA 16 (Cole et al., 2011), and BTA 20 (Cole et al., 2011; Meredith et al., 2013).

We targeted 6 regions for fine mapping. The regions were selected based on association signal strengths as evidence of association with multiple mastitis phenotypes. The number of targeted regions was arbitrarily restricted to 6 QTL for mastitis. The SNP density in the sequence data was not uniform across the targeted regions. We used SNP with imputation certainty $\geq 0.90$. The marker density, after quality control, varied from 3,155 per $\mathrm{Mb}$ on BTA 13 to 5,381 per $\mathrm{Mb}$ on BTA 19. The marker density for the HD SNP array was also lowest for the targeted region on BTA 13 (265/ $\mathrm{Mb})$ compared with $338 / \mathrm{Mb}$ on BTA 19. The higher HD marker density may have played a role in getting more accurate imputation for sequence-level variants, as imputation accuracy can vary widely depending on the surrounding LD structure (de Bakker et al., 2008). The LD structure in our targeted regions varied widely (Supplementary Figure S2, panels A to F; http:// dx.doi.org/10.3168/jds.2014-8141) and this may also have affected the accuracy of SNP imputation.

In this study, we used EBV of progeny-tested sires as response variables. Estimated breeding values contain information from other relatives of evaluated bulls, unlike deregressed EBV (deregressed proofs). Ekine et al. (2014) reported higher false-positive rates using EBV as response variables in simulated GWAS. However, their study was based on a small sample size $(\sim 1,010$ measured individuals), which reduced the reliability of EBV. Our study was based on EBV of progeny-tested bulls with hundreds of daughter records. The average reliability of EBV for CM in our study was $79 \%$ (range between 20 and 98\%). Guo et al. (2010) and Gao et al. (2013) reported that using EBV rather than daughter yield deviation as a response variable led to slightly higher accuracy of genomic predictions using simulation and real data, whereas a study on pig data by Ostersen et al. (2011) reported that using deregressed proofs rather than EBV as the response variable resulted in more reliable genomic predictions. The 6 targeted regions selected in the current study showed highly 
significant associations for multiple mastitis traits and are unlike to be false positives, due to the use of EBV as response variable. The model we used in the analyses assumed equal residual variances. However, the sires had unequal numbers of daughters, so effects of unequal residual variance may exist. Pryce et al. (2010) estimated the correlation between SNP solutions, estimated using the weighted and unweighted models, to be between 0.96 and 0.97 . Therefore, unequal residual variances are unlikely to have sizeable effects on the association results presented here.

\section{Limitation of Mapping Causal Mutation in Cattle Due to LD Structure}

Fitting the top associated SNP as a cofactor in the model yielded no additional significant associations in the targeted region, except on BTA 6. A SNP (modeled as a cofactor) in LD with other causal polymorphism(s) in the region will absorb the effects of additional causal factors proportional to the $\operatorname{LD}\left(\mathrm{r}^{2}\right)$ between the cofactor and the causal mutation quantitative trait nucleotide. This may be the reason we did not observe additional SNP with significant associations after a cofactor was fit. Therefore, we cannot rule out a scenario in which multiple genes affecting $\mathrm{CM}$ and SCC are located within the selected regions.

Using multiple-breed data has shown advantages for mapping causal factors; for example, in dogs (Karlsson et al. 2007). However, those successes in mapping causal factors were primarily found for Mendelian traits. The high prevalence of specific diseases within dog breeds suggests that a limited number of loci underlie each disease, making genetic dissection potentially more tractable (Chase et al. 2002). In contrast, mastitis resistance is highly polygenic in nature and the 6 targeted QTL in the current study explained only $8.9 \%$ of the total genetic variance for $\mathrm{CM}$, which ranged from 0.6 to $3.0 \%$ for individual QTL. Besides, multiple-breed data will only help map mutations that predate breed divergence or mutations that have introgressed into Jersey and Nordic Red cattle from Holstein cattle. Lund et al. (2007) and Sahana et al. (2008) mapped QTL in Nordic Red cattle using linkage analysis. However, QTL identified in Nordic Red were not among the top-ranking QTL in Nordic Holstein cattle, which could be due to different QTL segregating in different breeds. Even within Holstein populations from different countries, candidate genes predicted for the overlapping QTL (e.g., BTA6 at $\sim 88-90 \mathrm{Mb}$ ) are different (Cole et al., 2011; Sodeland et al., 2011; Abdel-Shafy et al., 2014). This indicates multiple causative factors for QTL located across multiple genes. Although one or several of the variants showing the strongest association may be causative variants, it is possible that the actual mutations may have been missed during sequence processing, filtering, or imputation. It is also possible that multiple genes in the targeted regions affect $\mathrm{CM}$ and that the most significant SNP is in LD with multiple QTL and not the causal polymorphism itself. Indeed, our ability to predict functionality is incomplete, as functionally important variants may be located in unannotated regions. Causal polymorphisms may also be insertion/ deletion polymorphisms or structural variants such as indels or copy number variants, which were not analyzed in the present study. Whole-genome sequencing with deeper coverage (e.g., $20 \times$ or $30 \times$ ) may improve variant prediction, and analyses of structural variants may help pinpoint candidate genes and causal variants.

\section{CONCLUSIONS}

Association analyses with HD SNP arrays for CM traits in Nordic Holstein cattle identified several QTL regions, and a subset was followed with whole-genome sequencing data. This study used Holstein cattle as a discovery population and Nordic Red and Jersey cattle for confirmation of the identified QTL from Holstein cattle. The QTL on BTA 6, 13, and 19 were confirmed in Nordic Red cattle, whereas BTA 16 and 20 were confirmed in Jersey cattle. Several potential candidate genes were identified. However, due to high LD, it was not possible to specify genes or polymorphisms as causal factors for any of the regions.

\section{ACKNOWLEDGMENTS}

We are grateful to the Danish Cattle Federation/ NAV (Aarhus, Denmark) for providing the phenotypic data used in this study. This work was supported by a grant (no. 3405-10-0137) funded jointly by the Green Development and Demonstration Program of the Danish Ministry of Food, Agriculture and Fisheries (Copenhagen, Denmark); the Milk Levy Fund; Viking Genetics (Randers, Denmark); and Nordic Cattle Genetic Evaluation (Aarhus, Denmark). Semen samples were provided by Viking Genetics. The 1,000 Bull Genomes Project is kindly acknowledged for sharing data to impute the genome sequence. Two anonymous reviewers provided very helpful comments on this manuscript. G. Sahana, B. Guldbrandtsen, and M. S. Lund conceived and designed the experiment; G. Sahana, B. Guldbrandtsen, and R. F. Brøndum analyzed the data; B. Thomsen, L. E. Holm, F. Panitz, C. Bendixen, and M. S. Lund contributed reagents/materials/analysis tools; and G. Sahana and B. Thomsen wrote the paper. All authors contributed to the discussion of the results, read, and approved the final manuscript. 


\section{REFERENCES}

Abdel-Shafy, H., R. H. Bortfeldt, M. Reissmann, and G. A. Brockmann. 2014. Validation of somatic cell score-associated loci identified in a genome-wide association study in German Holstein cattle. J. Dairy Sci. 97:2481-2486.

Adzhubei, I. A., S. Schmidt, L. Peshkin, V. E. Ramensky, A. Gerasimova, P. Bork, A. S. Kondrashov, and S. R. Sunyaev. 2010. A method and server for predicting damaging missense mutations. Nat. Methods 7:248-249.

Akaike, H. 1974. New look at the statistical model identification. IEEE Trans. Automat. Contr. AC19:716-723.

Baumann, H., and G. G. Wong. 1989. Hepatocyte-stimulating factor III shares structural and functional identity with leukemia-inhibitory factor. J. Immunol. 143:1163-1167.

Browning, B. L., and S. R. Browning. 2009. A unified approach to genotype imputation and haplotype-phase inference for large data sets of trios and unrelated individuals. Am. J. Hum. Genet. $84: 210-223$.

Busenlehner, L. S., J. Ålander, C. Jegerscöhld, P. J. Holm, P. Bhakat, H. Hebert, R. Morgenstern, and R. N. Armstrong. 2007. Location of substrate binding sites within the integral membrane protein microsomal glutathione transferase-1. Biochemistry 46:2812-2822.

Chase, K., D. R. Carrier, F. R. Adler, T. Jarvik, E. A. Ostrander, T. D. Lorentzen, and K. G. Lark. 2002. Genetic basis for systems of skeletal quantitative traits: Principal component analysis of the canid skeleton. Proc. Natl. Acad. Sci. USA 99:9930-9935.

Cole, J. B., G. R. Wiggans, L. Ma, T. S. Sonstegard, T. J. Lawlor Jr., B. A. Crooker, C. P. Van Tassell, J. Yang, S. Wang, L. K. Matukumalli, and Y. Da. 2011. Genome-wide association analysis of thirty one production, health, reproduction and body conformation traits in contemporary U.S. Holstein cows. BMC Genomics 12:408.

de Bakker, P. I. W., M. A. R. Ferreira, X. Jia, B. M. Neale, S. Raychaudhuri, and B. F. Voight. 2008. Practical aspects of imputation-driven meta-analysis of genome-wide association studies. Hum. Mol. Genet. 17:R122-R128.

de Roos, A. P., B. J. Hayes, R. J. Spelman, and M. E. Goddard. 2008. Linkage disequilibrium and persistence of phase in Holstein-Friesian, Jersey and Angus cattle. Genetics 179:1503-1512.

Ekine, C. C., S. J. Rowe, S. C. Bishop, and D.-J. de Koning. 2014. Why breeding values estimated using familial data should not be used for genome-wide association studies. G3 (Bethesda) 4:341-347.

Escary, J.-L., J. Perreau, D. Duménil, S. Ezine, and P. Brûlet. 1993. Leukaemia inhibitory factor is necessary for maintenance of haematopoietic stem cells and thymocyte stimulation. Nature 363:361-364

Gao, H., M. S. Lund, Y. Zhang, and G. Su. 2013. Accuracy of genomic prediction using different models and response variables in the Nordic Red cattle population. J. Anim. Breed. Genet. 130:333340 .

Guo, G., M. S. Lund, Y. Zhang, and G. Su. 2010. Comparison between genomic predictions using daughter yield deviation and conventional estimated breeding value as response variables. J. Anim. Breed. Genet. 127:423-432.

Heringstad, B., Y. M. Chang, D. Gianola, and G. Klemetsdal. 2005. Genetic association between susceptibility to clinical mastitis and protein yield in Norwegian dairy cattle. J. Dairy Sci. 88:15091514.

Hewison, M. 2011. Antibacterial effects of vitamin D. Nat. Rev. Endocrinol. 7:337-345.

Höglund, J. K. 2013. Gene mapping of reproduction traits in dairy cattle. PhD Thesis. Aarhus University, Tjele, Denmark.

Ikeda, T., H. Kawaguchi, S. Kamekura, N. Ogata, Y. Mori, K. Nakamura, S. Ikegawa, and U. Chung. 2005. Distinct roles of Sox5, Sox6, and Sox9 in different stages of chondrogenic differentiation. J. Bone Miner. Metab. 23:337-340.

Jhamandas, J. H., and V. Goncharuk. 2013. Role of neuropeptide FF in central cardiovascular and neuroendocrine regulation. Front. Endocrinol. (Lausanne) 4:8.
Johansson, K., S. Eriksson, J. Pösö, U. S. Nielsen, and G. P. Aamand. 2007. Predictive ability of different models for clinical mastitis in joint genetic evaluation for Sweden, Denmark and Finland. Abstract no. 1746 in Book of Abstracts of the 58th Annu. Mtg. Eur. Fed. Anim. Sci., Dublin, Ireland. Wageningen Academic Publishers, Wageningen, the Netherlands.

Johansson, K., J. Järvliden, V. Gogvadze, and R. Morgenstern. 2010. Multiple roles of microsomal glutathione transferase 1 in cellular protection: a mechanistic study. Free Radic. Biol. Med. 49:16381645.

Johnson, D. S., and Y. H. Chen. 2012. Ras family of small GTPases in immunity and inflammation. Curr. Opin. Pharmacol. 12:458-463.

Kadri, N. K., B. Guldbrandtsen, P. Sørensen, and G. Sahana. 2014 Comparison of genome-wide association methods in analyses of admixed populations with complex familial relationships. PLoS ONE 9:e88926.

Karlsson, E. K., I. Baranowska, C. M. Wade, N. H. Salmon Hillbertz, M. C. Zody, N. Anderson, T. M. Biagi, N. Patterson, G. R. Pielberg, E. J. Kulbokas III, K. E. Comstock, E. T. Keller, J. P. Mesirov, H. von Euler, O. Kämpe, Å. Hedhammar, E. S. Lander, G. Andersson, L. Andersson, and K. Lindblad-Toh. 2007. Efficient mapping of Mendelian traits in dogs through genome-wide association. Nat. Genet. 39:1321-1328.

Kwan, K. Y., M. M. S. Lam, Ž. Krsnik, Y. I. Kawasawa, V. Lefebvre, and N. Sestan. 2008. SOX5 postmitotically regulates migration, postmigratory differentiation, and projections of subplate and deep-layer neocortical neurons. Proc. Natl. Acad. Sci. USA 105:16021-16026.

Lai, T., D. Jabaudon, B. J. Molyneaux, E. Azim, P. Arlotta, J. R. Menezes, and J. D. Macklis. 2008. SOX5 controls the sequential generation of distinct corticofugal neuron subtypes. Neuron $57: 232-247$.

Lecron, J.-C., M. Minault, M. Allard, P. Goube de Laforest, J. Gombert, and G. Simonnet. 1992. Modulation of human lymphocyte proliferation by FLFQPQRFamide, a FMRFamide-like peptide with anti-opiate properties. J. Neuroimmunol. 38:1-8.

Li, H., and R. Durbin. 2009. Fast and accurate short read alignment with Burrows-Wheeler transform. Bioinformatics 25:1754-1760.

Li, H., B. Handsaker, A. Wysoker, T. Fennell, J. Ruan, N. Homer, G. Marth, G. Abecasis, and R. Durbin., and 1000 Genome Project Data Processing Subgroup. 2009. The Sequence Alignment/Map format and SAMtools. Bioinformatics 25:2078-2079.

Li, H., J. Ruan, and R. Durbin. 2008. Mapping short DNA sequencing reads and calling variants using mapping quality scores. Genome Res. 18:1851-1858.

Linker, R. A., N. Kruse, S. Israel, T. Wei, S. Seubert, A. Hombach, B. Holtmann, F. Luhder, R. M. Ransohoff, M. Sendtner, and R. Gold. 2008. Leukemia inhibitory factor deficiency modulates the immune response and limits autoimmune demyelination: A new role for neurotrophic cytokines in neuroinflammation. J. Immunol. 180:2204-2213.

Lund, M. S., B. Guldbrandtsen, A. J. Buitenhuis, B. Thomsen, and C. Bendixen. 2008. Detection of quantitative trait loci in Danish Holstein cattle affecting clinical mastitis, somatic cell score, udder conformation traits, and assessment of associated effects on milk yield. J. Dairy Sci. 91:4028-4036.

Lund, M. S., J. Jensen, and P. H. Petersen. 1999. Estimation of genetic and phenotypic parameters for clinical mastitis, somatic cell production deviance, and protein yield in dairy cattle using Gibbs sampling. J. Dairy Sci. 82:1045-1051.

Lund, M. S., A. P. Roos, A. G. Vries, T. Druet, V. Ducrocq, S. Fritz, F. Guillaume, B. Guldbrandtsen, Z. Liu, R. Reents, C. Schrooten, F. Seefried, and G. Su. 2011. A common reference population from four European Holstein populations increases reliability of genomic predictions. Genet. Sel. Evol. 43:43.

Lund, M. S., G. Sahana, L. Andersson-Eklund, N. Hastings, A. Fernandez, N. Schulman, B. Thomsen, S. Viitala, J. L. Williams, A. Sabry, H. Viinalass, and J. Vilkki. 2007. Joint analysis of quantitative trait loci for clinical mastitis and somatic cell score on five 
chromosomes in three Nordic dairy cattle breeds. J. Dairy Sci. 90:5282-5290.

Madsen, P., and J. Jensen. 2012. DMU - A user's guide. A package for analysing multivariate mixed models. Version 6 , release 5.1. University of Aarhus, Faculty of Agricultural Sciences (DJF), Dept. of Genetics and Biotechnology, Research Centre Foulum, Tjele, Denmark.

McKenna, A., M. Hanna, E. Banks, A. Sivachenko, K. Cibulskis, A. Kernytsky, K. Garimella, D. Altshuler, S. Gabriel, M. Daly, and M. A. DePristo. 2010. The Genome Analysis Toolkit: A MapReduce framework for analyzing next-generation DNA sequencing data. Genome Res. 20:1297-1303.

McLaren, W., B. Pritchard, D. Rios, Y. A. Chen, P. Flicek, and F. Cunningham. 2010. Deriving the consequences of genomic variants with the Ensembl API and SNP Effect Predictor. Bioinformatics 26:2069-2070.

Meredith, B. K., D. P. Berry, F. Kearney, E. K. Finlay, A. G. Fahey, D. G. Bradley, and D. J. Lynn. 2013. A genome-wide association study for somatic cell score using the Illumina high-density bovine BeadChip identifies several novel QTL potentially related to mastitis susceptibility. Front. Genet. 4:229.

Minault, M., J. C. Lecron, S. Labrouche, G. Simonnet, and J. Gombert 1995. Characterization of binding sites for neuropeptide FF on T lymphocytes of the Jurkat cell line. Peptides 16:105-111.

Morita, Y., T. Shibutani, N. Nakanishi, K. Nishikura, S. Iwai, and I. Kuraoka. 2013. Human endonuclease $\mathrm{V}$ is a ribonuclease specific for inosine-containing RNA. Nat. Commun. 4:2273.

Mosialou, E., F. Piemonte, C. Andersson, R. M. Vos, P. J. van Bladeren, and R. Morgenstern. 1995. Microsomal glutathione transferase: Lipid-derived substrates and lipid dependence. Arch. Biochem. Biophys. 320:210-216.

Ng, P. C., and S. Henikoff. 2001. Predicting deleterious amino acid substitutions. Genome Res. 11:863-874.

Nilsen, H., H. G. Olsen, B. Hayes, T. Nome, E. Sehested, M. Svendsen, T. H. E. Meuwissen, and S. Lien. 2009. Characterization of a QTL region affecting clinical mastitis and protein yield on BTA6. Anim. Genet. 40:701-712.

Ostersen, T., O. F. Christensen, M. Henryon, B. Nielsen, G. Su, and P. Madsen. 2011. Deregressed EBV as the response variable yield more reliable genomic predictions than traditional EBV in purebred pigs. Genet. Sel. Evol. 43:38.

Pryce, J. E., S. Bolormaa, A. J. Chamberlain, P. J. Bowman, K. Savin, M. E. Goddard, and B. J. Hayes. 2010. A validated genome-wide association study in 2 dairy cattle breeds for milk production and fertility traits using variable length haplotypes. J. Dairy Sci. 93:3331-3345.

Purcell, S., B. Neale, K. Todd-Brown, L. Thomas, M. A. Ferreira, D. Bender, J. Maller, P. Sklar, P. I. de Bakker, M. J. Daly, and
P. C. Sham. 2007. PLINK: A tool set for whole-genome association and population-based linkage analyses. Am. J. Hum. Genet. $81: 559-575$.

Ricklin, D., G. Hajishengallis, K. Yang, and J. D. Lambris. 2010. Complement: A key system for immune surveillance and homeostasis. Nat. Immunol. 11:785-797.

Sahana, G., B. Guldbrandtsen, L. Janss, and M. S. Lund. 2010. Comparison of association mapping methods in a complex pedigreed population. Genet. Epidemiol. 34:455-462.

Sahana, G., B. Guldbrandtsen, B. Thomsen, and M. S. Lund. 2013 Confirmation and fine-mapping of clinical mastitis and somatic cell score QTL in Nordic Holstein cattle. Anim. Genet. 44:620-626.

Sahana, G., M. S. Lund, L. Andersson-Eklund, N. Hastings, A. Fernandez, T. Iso-Touru, B. Thomsen, S. Viitala, P. Sorensen, J. L. Williams, and J. Vilkki. 2008. Fine-mapping QTL for mastitis resistance on BTA9 in three Nordic red cattle breeds. Anim. Genet. 39:354-362.

Schwarz, G. 1978. Estimating the dimension of a model. Ann. Stat. 6:461-464.

Sherry, S. T., M. Ward, and K. Sirotkin. 2000. Use of molecular variation in the NCBI dbSNP database. Hum. Mutat. 15:68-75.

Sodeland, M., M. P. Kent, H. G. Olsen, M. A. Opsal, M. Svendsen, E. Sehested, B. J. Hayes, and S. Lien. 2011. Quantitative trait loci for clinical mastitis on chromosomes 2, 6, 14 and 20 in Norwegian Red cattle. Anim. Genet. 42:457-465.

$\mathrm{Su}$, G., R. F. Brøndum, P. Ma, B. Guldbrandtsen, G. P. Aamand, and M. S. Lund. 2011. Genomic prediction using high-density SNP markers in Nordic Holstein and Red. Interbull Bull. 44:157-161.

Sun, Y.-L., X.-Y. Zhang, T. Sun, N. He, J.-Y. Li, Y. Zhuang, Q. Zeng, J. Yu, Q. Fang, and R. Wang. 2013. The anti-inflammatory potential of neuropeptide FF in vitro and in vivo. Peptides 47:124-132.

Yamamoto, N., and S. Homma. 1991. Vitamin $\mathrm{D}_{3}$ binding protein (group-specific component) is a precursor for the macrophage-activating signal factor from lysophosphatidylcholine-treated lymphocytes. Proc. Natl. Acad. Sci. USA 88:8539-8543.

Yu, J., G. Pressoir, W. H. Briggs, I. Vroh Bi, M. Yamasaki, J. F. Doebley, M. D. McMullen, B. S. Gaut, D. M. Nielsen, J. B. Holland, S. Kresovich, and E. S. Buckler. 2006. A unified mixed-model method for association mapping that accounts for multiple levels of relatedness. Nat. Genet. 38:203-208.

Zeng, H., K. Yang, C. Cloer, G. Neale, P. Vogel, and H. Chi. 2013. mTORC1 couples immune signals and metabolic programming to establish $\mathrm{T}_{\mathrm{reg}}$-cell function. Nature 499:485-490.

Zimin, A. V., A. L. Delcher, L. Florea, D. R. Kelley, M. C. Schatz, D. Puiu, F. Hanrahan, G. Pertea, C. P. Van Tassell, T. S. Sonstegard, G. Marçais, M. Roberts, P. Subramanian, J. A. Yorke, and S. L. Salzberg. 2009. A whole-genome assembly of the domestic cow, Bos taurus. Genome Biol. 10:R42. 